\title{
Dapsone in dermatology and beyond
}

\author{
Gottfried Wozel · Christian Blasum
}

Received: 25 February 2013/Revised: 30 July 2013/ Accepted: 19 August 2013/Published online: 6 December 2013

(C) The Author(s) 2013. This article is published with open access at Springerlink.com

\begin{abstract}
Dapsone $\left(4,4^{\prime}\right.$-diaminodiphenylsulfone) is an aniline derivative belonging to the group of synthetic sulfones. In 1937 against the background of sulfonamide era the microbial activity of dapsone has been discovered. Shortly thereafter, the use of dapsone to treat non-pathogen-caused diseases revealed alternate antiinflammatory mechanisms that initially were elucidated by inflammatory animal models. Thus, dapsone clearly has dual functions of both: antimicrobial/antiprotozoal effects and anti-inflammatory features similarly to non-steroidal anti-inflammatory drugs. The latter capabilities primarily were used in treating chronic inflammatory disorders. Dapsone has been investigated predominantly by in vitro methods aiming to get more insights into the effect of dapsone to inflammatory effector cells, cytokines, and/or mediators, such as cellular toxic oxygen metabolism, myoloperoxidase-/halogenid system, adhesion molecules, chemotaxis, membraneassociated phospholipids, prostaglandins, leukotrienes, interleukin-8, tumor necrosis factor $\alpha$, lymphocyte functions, and tumor growth. Moreover, attention has been paid to mechanisms by which dapsone mediates effects in more complex settings like impact of lifespan, stroke, glioblastoma, or as anticonvulsive agent. Additionally, there are
\end{abstract}

G. Wozel ( $\square)$

Study Centre for Clinical Trials, Dermatology, Gesellschaft für Wissens- und Technologietransfer der Technischen Universität Dresden mbH, Blasewitzer Str. 43, 01307 Dresden, Germany

e-mail: Gkatharina.bluemlein@uniklinikum-dresden.de

C. Blasum

Private Practice of Dermatology, Marktplatz 25,

73728 Esslingen, Germany

e-mail: Dr.Christian.Blasum@t-online.de some dermatological investigations in human being using dapsone and its metabolites (e.g., leukotriene $\mathrm{B}_{4}$-induced chemotaxis, ultraviolet-induced erythema). It could be established that dapsone metabolites by their own have anti-inflammatory properties. Pharmacology and mechanisms of action are determining factors for clinical use of dapsone chiefly in neutrophilic and/or eosinophilic dermatoses and in chronic disorders outside the field of dermatology. The steroid-sparing effect of dapsone is useful for numerous clinical entities. Future avenues of investigations will provide more information on this fascinating and essential agent.

Keywords Dapsone - Antiinflammatory mechanisms of action - Adverse effects - Therapeutic strategies · Use in dermatology · Non-dermatological disorders

$\begin{array}{ll}\text { Abbreviations } & \\ \text { AA } & \text { Arachidonic acid } \\ \text { AB } & \text { Antibody } \\ \text { AIDS } & \text { Acquired immunodeficiency syndrome } \\ \text { AIP } & \alpha \text {-1-Protease inhibitor } \\ \text { ALAT } & \text { Alanine-aminotransferase } \\ \text { ASAT } & \text { Aspartate-aminotransferase } \\ \text { AUC } & \text { Area under curve } \\ \text { C. elegans } & \text { Caenorhabditis elegans } \\ \text { CBC } & \text { Complete blood count } \\ \text { ChPhTF } & \text { Cholinephosphotransferase } \\ \text { CNS } & \text { Central nervous system } \\ \text { C5a } & \text { Complement component 5a } \\ \text { COX } & \text { Cyclooxygenase } \\ \text { CP } & \text { Clobetasol-17-propionate } \\ \text { CXCR } & \text { CXC chemokine receptor } \\ \text { CYP 450/2E1 } & \text { Cytochrome P450/2E1 }\end{array}$




\section{DDS \\ DDS-NOH \\ DTH \\ EAS \\ EGF/EGFR}

\section{FACS}

FDA

FMLP

G6PD

5-HETE

$\mathrm{HS}$

$\mathrm{IC}_{50}$

$\mathrm{Ig} \mathrm{A} / \mathrm{G} / \mathrm{E}$

IL-8

IL-1 $\beta$

INF $\gamma$

ITP

$\mathrm{KC}$

6KF1 $\alpha$

LDCF

LE

LFA

5-LOX

$\mathrm{LTB}_{4} / \mathrm{LTC}_{4}$

LPS

LC

MADDS

MEST

met-Hb

MPO

mRNA

mTOR

$\mathrm{NADPH}$

NSAID

NIHSS

PAF

PBMC

$\mathrm{PGD}_{2}$

PHA

PMA

PMN

RA

ROS

SOD

TNF $\alpha$

UDP

UVA/UVB

VEGF/VEGFR
4,4'-Diaminodiphenylsulfone

Dapsone hydroxylamine

Delayed type hypersensitivity

Endotoxin activated autologous serum

Epidermal growth factor/epidermal growth factor receptor

Fluorescence-activated cell sorter

Food and drug administration

$N$-formyl-methionyl-leucyl-

phenylalanine

Glucose-6-phosphate dehydrogenase

5-Hydroxyeicosatetraenoic acid

Hypersensitivity syndrome

Half-maximal inhibitory concentration

Immunoglobulin A/G/E

Interleukin 8

Interleukin $1 \beta$

Interferon $\gamma$

Idiopathic thrombocytopenic purpura

Keratinocyte

6-Keto-prostaglandin $\mathrm{F}_{1} \alpha$

Leukocyte-derived chemotactic factor

Lupus erythematosus

Leukocyte function antigen

5-Lipoxygenase

Leukotriene $\mathrm{B}_{4} / \mathrm{C}_{4}$

Lipopolysaccharide

Lymphocyte

Monoacetyl dapsone

Mouse ear swelling test

Methemoglobin

Myeloperoxidase

Messenger ribonucleic acid

Mammalian target of rapamycin

Reduced nicotinamide adenine

dinucleotide phosphate

Non-steroidal anti-inflammatory drug

National Institute of Health Stroke Scale

Platelet-activating factor

Peripheral blood mononuclear cell

Prostaglandin $\mathrm{D}_{2}$

Phytohemagglutinin

Phorbol myristate acetate

Polymorphonuclear leukocytes

Rheumatoid arthritis

Reactive oxygen species

Superoxide dismutase

Tumor necrosis factor $\alpha$

Uridine diphosphate

Ultraviolet A/B

Vascular endothelial growth factor/ VEGF receptor

\section{Introduction}

Dapsone was first synthesized in 1908 [63]. At that time, dapsone was not envisioned as a therapeutic agent, but was the result of pure chemical science ambition. Sulfone research in medicine started in 1937, when two groups in England and France were the first to investigate dapsone as an antimicrobial agent in the framework of sulfonamide research $[22,43,59]$. In this context, it is remarkable that certain congeners, but not the so-called parent sulfone dapsone, were the first sulfones used to treat gonorrhea [18, 123]. Later, introduction into the therapy of non-infectious diseases was not the result of systematic research, but virtually driven by fortune $[170,173]$.

Concerning the mechanisms of action, dapsone is characterized by dual function. It combines both antimicrobial/antiprotozoal properties and anti-inflammatory effects resembling those of non-steroidal anti-inflammatory drugs. In past decades, especially the hematological adverse effects of dapsone have induced intense efforts to develop substituted sulfones with improved risk-benefitratio. A parallel goal of research was the synthesis of parenteral application modalities. Interestingly, however, still today the oral application of dapsone constitutes the only sulfone used in systemic therapy.

The changeful history of dapsone has been covered in detail in the literature $[47,165,170]$. Therefore, this issue has been omitted from this survey. Rather, this paper will focus on the mechanisms of action of dapsone and consider important indications in dermatology and beyond as well as therapeutic consequences. In order to understand the mechanisms of action of sulfone and its adverse effects, knowledge of its pharmacology and metabolism in human beings and in inflammatory cells is mandatory.

\section{Chemistry and pharmacology}

Chemically, dapsone is an aniline derivative. As a sulfone, it shows the structure of a sulphur atom linking to two carbon atoms (Fig. 1). Solubility of dapsone varies over a wide range depending on the solvent used (e.g. water, $0.2 \mathrm{mg} / \mathrm{mL}$ vs. methanol, $52 \mathrm{mg} / \mathrm{mL}$ ). Following oral administration, dapsone is almost completely absorbed from the gut with bioavailability exceeding $86 \%$. Peak serum concentrations are attained within $2-8 \mathrm{~h}$. After ingestion of a single $50-300 \mathrm{mg}$ dose of dapsone, maximum serum concentrations range from 0.63 to $4.82 \mathrm{mg} / \mathrm{L}$ [2, 165, 181]. Under steady-state conditions, $100 \mathrm{mg} /$ day (the dose most frequently used) results in serum concentrations of $3.26 \mathrm{mg} / \mathrm{L}$ (maximum) and $1.95 \mathrm{mg} / \mathrm{L}$ (after 24 h) $[2,41,181]$. These dapsone serum concentrations 


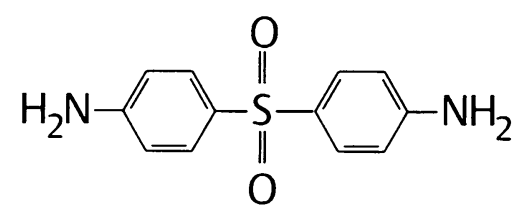

Fig. 1 Structural formula of dapsone (4,4'diaminodiphenylsulfone)

attained in vivo must be kept in mind when interpreting the results of in vitro investigations (see below). After absorption, dapsone undergoes enterohepatic circulation. It is metabolized by the liver but also by activated polymorphonuclear leukocytes (PMN) and mononuclear cells $[152,156]$. In the liver, dapsone is metabolized primarily through acetylation by $\mathrm{N}$-acetyltransferase to monoacteyldapsone (MADDS), and through hydroxylation by cytochrome P-450 enzymes, resulting in the generation of dapsone hydroxylamine (DDS-NOH) (Fig. 2). In fact, administration of dapsone has been utilized to determine the acetylation phenotype (rapid vs. slow acetylator). In terms of both efficacy and induction of adverse effects, the most important issue is the generation of DDS-NOH. This metabolic pathway also occurs in lesional skin of inflammatory dermatoses and is thought to be mediated by activated PMN [156]. Dapsone is distributed to virtually all organs. Dapsone is retained in skin, muscle, kidneys, and liver. Trace concentrations of the drug may be presented in these tissues up to 3 weeks after discontinuation of dapsone treatment. The drug is also distributed into sweat, saliva, sputum, tears, and bile. Dapsone is $50-90 \%$ bound to plasma proteins, whereas MADDS is almost completely bound to plasma proteins. It crosses the blood-brain barrier and placenta and is detectable in breast milk [20, 137].
Cases have been reported where dapsone therapy of the mother resulted in neonatal haemolysis and cyanosis [105]. Approximately $20 \%$ of dapsone is excreted as unchanged drug via urine, whereas $70-85 \%$ is eliminated as watersoluble metabolites after conjugation with glucuronic acid. This step is mediated by uridine diphosphate (UDP)-glucuronosyltransferase. Additionally, a small amount might be excreted in faeces including some yet unidentified metabolites. The complex metabolic pathway of dapsone has been reviewed in detail several times $[156,159,164$, $165,178,181]$.

Metabolism of dapsone in cell cultures has not been studied as extensively [17]. In part, this can be attributed to the chemical properties of dapsone, which make it a difficult-to-handle compound [165]. First findings concerning the metabolism of dapsone in cell cultures were presented by Drayer et al. [49] and the Canadian group of Uetrecht et al. [156]. Following incubation of PMN- and zymosanactivated human PMN with dapsone, high-pressure liquid chromatography and gas chromatography/mass spectroscopy demonstrated the production of dapsone hydroxylamine $\left(-\mathrm{NO}_{2}\right)$, (Fig. 9) and a chlorine-substituted derivative of dapsone (-Cl) (chlorodapsone) (Fig. 10). Without prior stimulation, neither DDS-NOH nor the nitro derivative were detectable. The authors postulate the biotransformation as depicted in Fig. 3. Activation of leukocytes results in the induction of the respiratory burst pathway with consecutive production of reactive oxygen-species (ROS) such as ${ }^{1} \mathrm{O}_{2}$ ( singlet- $\mathrm{O}_{2}$ ), $\mathrm{H}_{2} \mathrm{O}_{2}$ or $\mathrm{OH}^{-}$. During this process, myeloperoxidase (MPO) uses dapsone as substrate resulting in the generation of DDS-NOH via oxidation. Finally, by a further non-enzymatic oxidation process, the nitro derivative of dapsone is generated (Fig. 11).
Fig. 2 The two major metabolic pathways of dapsone (MADDS monoacetyldapsone, DDS-NOH dapsone hydroxylamine)

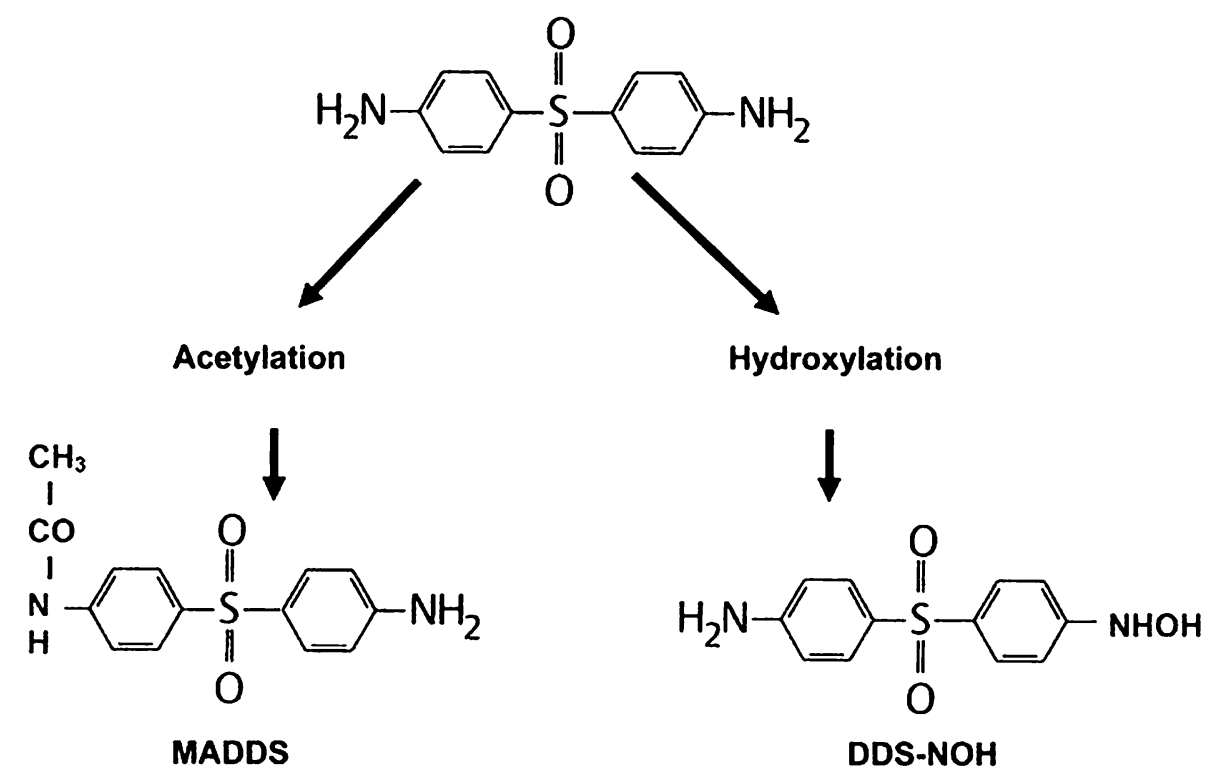


Fig. 3 Dapsone metabolism in human PMN and mononuclear cells after activation by phorbol myristate acetate (PMA) and oxidation path by $\mathrm{NaOCl}$ (according to Uetrecht et al. [156])

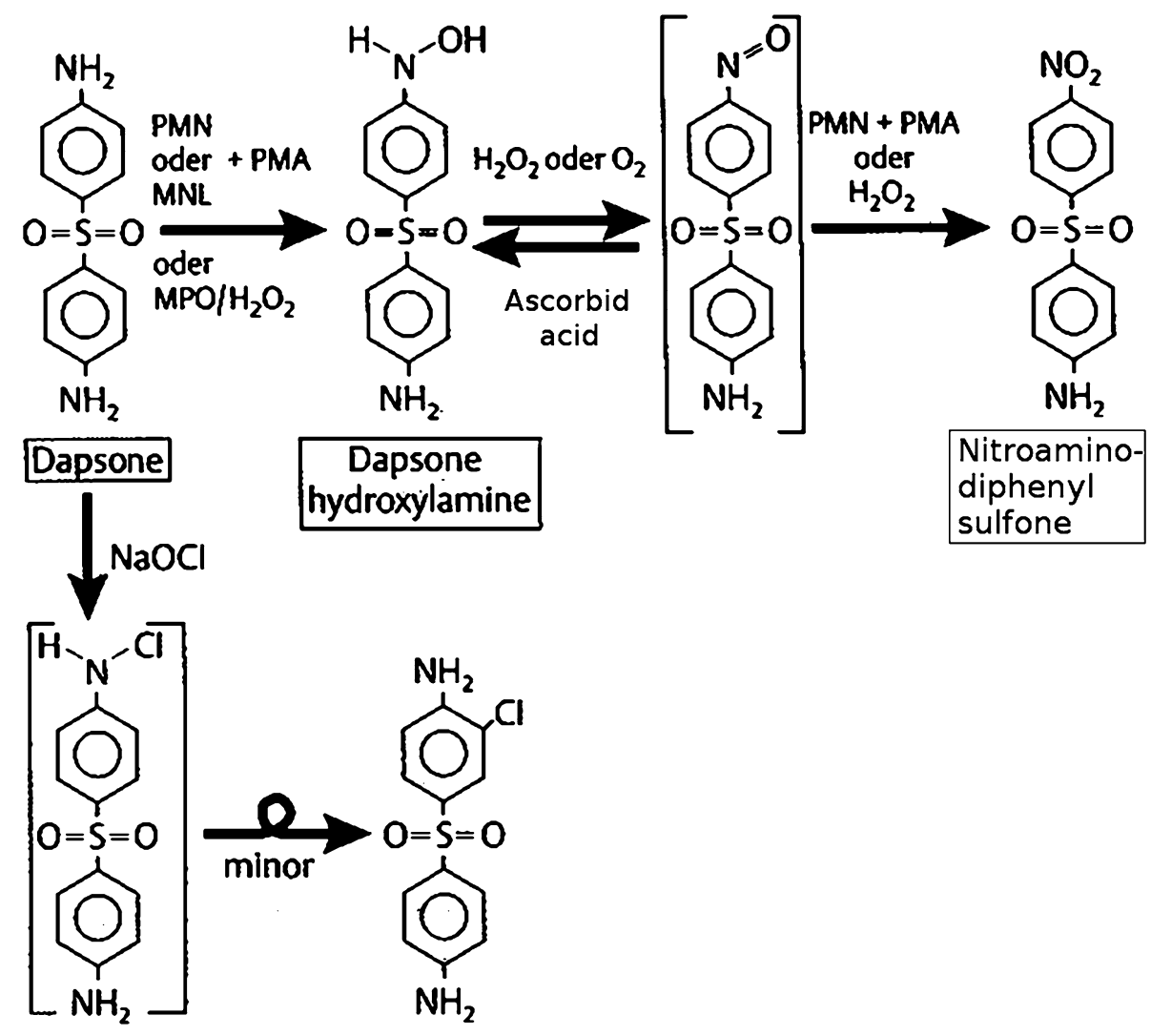

Chlorodapsone

Controls in cell-free settings using purified myeloperoxidase and $\mathrm{H}_{2} \mathrm{O}_{2}$ confirmed these findings. In contrast, adding catalase or sodium azide, respectively, led to a dose-dependent inhibition of the oxidation of dapsone. The authors were not able to demonstrate a presumptive alternative enzymatic pathway of hydroxylation of dapsone through the prostaglandin pathway, as classic inhibitors like acetylsalicylic acid or indometacin did not induce a decrease of oxidation. Dapsone metabolism in human mononuclear cells has been demonstrated to be quite similar [156].

When dapsone is administered, there is equilibrium between acetylation and deacetylation. Thus, there is the possibility that PMN in peripheral blood are exposed both to dapsone and its metabolites. These metabolites like DDS-NOH have been shown to be pharmacologically active. However, they have been made responsible not only for anti-inflammatory mechanisms (e.g., inhibition of chemotaxis) but also for a number of side effects. To date, this has been clearly documented for DDS-NOH [35]. Interestingly, Khan et al. [95] recently demonstrated that human keratinocytes which had been stimulated by various cytokines like tumor necrosis factor $\alpha$ (TNF- $\alpha)$, interleukin $1 \beta$ (Il-1 $\beta)$, and interferon $\gamma($ INF- $\gamma)$ can produce DDS$\mathrm{NOH}$ as well.

\section{Antimicrobial activity}

As an antimicrobial agent, dapsone is bacteriostatic in action. It inhibits the synthesis of dihydrofolic acid through by competing with para-aminobenzoic acid for the active site of dihydropteroate synthetase [35, 41], thus resembling the action of sulphonamides. Sulfones were found to suppress the growth of various pathogenic bacteria such as streptococci, staphylococci, pneumococci, mycobacteria, and other strains. The mechanism of action of topical dapsone in the treatment of acne vulgaris may result from a combination of both antiinflammatory and antimicrobial effects. In vitro, dapsone has some antibacterial activity against Propionibacterium acnes. Owing to its antimicrobial activities, dapsone is clearly playing a role in the treatment of certain infectious diseases (see section "Indications") [67].

\section{Anti-inflammatory mechanisms of action}

Animal studies

In the 1970s, dapsone was studied in numerous inflammation models in animals. Experiments were conducted 
Table 1 Investigations of dapsone in common animal inflammatory models

\begin{tabular}{|c|c|c|c|}
\hline Model & Dose range & Authors & References \\
\hline A single dose studies & $\mathrm{mg} / \mathrm{kg}$ & & \\
\hline Carrageenan-oedema (rat) & $36-160$ & $\begin{array}{l}\text { Capstick and } \\
\text { Lewis }\end{array}$ & {$[23]$} \\
\hline Kaolin-induced oedema (rat) & $11-100$ & Lewis et al. & {$[102]$} \\
\hline Zymosan-induced oedema (rat) & $10-100$ & Gemmel et al. & {$[64]$} \\
\hline Reverse passive Arthus-type reaction (rat) & $10-100$ & & \\
\hline UV erythema (guinea pig) & $\mathrm{ED}_{50}-160$ & Lewis et al. & {$[102]$} \\
\hline B multiple dose studies & $\mathrm{mg} / \mathrm{kg} /$ day & & \\
\hline $\begin{array}{l}\text { Reverse passive Arthus-type reaction (guinea } \\
\text { pig) }\end{array}$ & $2-5$ & Ruzicka et al. & {$[131]$} \\
\hline Aktive Arthus-type reaktion (guinea pig) & $5-50$ & $\begin{array}{l}\text { Thompson and } \\
\text { Souhami }\end{array}$ & {$[150]$} \\
\hline Cotton wool pellet granuloma (rat) & 200 & $\begin{array}{l}\text { Capstick and } \\
\text { Lewis }\end{array}$ & {$[23]$} \\
\hline Carrageenan-impregnated & $50-200$ & Lewis et al. & {$[102]$} \\
\hline \multicolumn{4}{|l|}{ Cotton wool pellet granuloma (rat) } \\
\hline \multirow[t]{2}{*}{ Adjuvant arthritis (rat) } & $100-200$ & $\begin{array}{l}\text { Capstick and } \\
\text { Lewis }\end{array}$ & {$[23]$} \\
\hline & & Lewis et al. & [102] \\
\hline Hypervitaminosis A (rabbit) & 25 & Barranco & {$[8]$} \\
\hline $\begin{array}{l}\text { Arachidonic acid-induced mouse ear swelling } \\
\text { test (AA-MEST) }\end{array}$ & $0.1 ; 1 ; 5 ; 10 \%$ & Christoph & {$[29]$} \\
\hline Anthralin-induced MEST & $\begin{array}{l}\text { Topically and } \\
\text { systemically }\end{array}$ & Salomon & {$[135]$} \\
\hline
\end{tabular}

especially with small mammals like mice, rats and guinea pigs (Table 1). Results of these studies showed wide variations in anti-inflammatory efficacy. Whereas some authors were able to demonstrate pronounced anti-inflammatory activities (e.g. in anthralin-induced mouse ear swelling test (MEST), others failed to do so (e.g. in arachidonic acid-induced MEST). Gemmel et al. [64] and Lewis et al. [102], for example, showed that the antiinflammatory action of dapsone differs from that of aspirinlike non-steroidal anti-inflammatory drugs (NSAID's).

Hence, it is difficult to draw reliable conclusions regarding the mechanisms of action of dapsone in sulfonesensitive diseases. In this respect, several factors have to be considered. Amongst others, the inflammation models used are only poorly characterised on phenotypic and genotypic levels. Often, dapsone-concentrations applied were considerably exceeding those achieved under therapy. Apart from that, single dose application cannot be readily compared with repeated doses. Finally, testing conditions varied substantially (e.g. pre-therapeutic vs. post-therapeutic application of the sulfone). Despite these limitations, dapsone can be attributed an anti-inflammatory potential that - cum grano salis_equals that of classic NSAID's. In the following, the impact of dapsone on isolated proinflammatory signal transduction pathways and on more complex disease processes is described in detail.

\section{Reactive oxygen species}

Historically, Japanese authors were the first in 1983 to attribute an oxygen-radical scavenging ability to dapsone [112-115, 121, 161]. In the works of this group, dapsone was shown to effectively lower the concentrations of $\mathrm{H}_{2} \mathrm{O}_{2}$ and of $\mathrm{OH}^{-}$as well as the activity of chemiluminescence when these parameters were studied during the process of oxidative activation PMN. However, dapsone did not alter the concentration of $\mathrm{O}_{2}{ }^{-}$. Experiments by van Baar et al. [unpublished data] confirmed these findings. Furthermore, the Japanese authors were able to demonstrate an effect of dapsone to reduce the concentrations of extracellular ROS as well as that of singulett ${ }^{1} \mathrm{O}_{2}$. In these experiments the xanthine/xanthine oxidase system had been tested in the absence of both PMN and superoxide dismutase (SOD). Accordingly, the $\mathrm{ROS}$-but not $\mathrm{O}_{2}{ }^{-}$-lowering effect of dapsone, is unlikely to be mediated by an interaction of dapsone and SOD. In contrast to these conclusions it was claimed by later publications that dapsone actually suppressed $\quad N$-formyl-methionyl-leucyl-phenylalanine (FLMP)-induced production of extracellular $\mathrm{O}_{2}{ }^{-}$[43]. More recent studies by Suda et al. [148] yielded comparable data with those of Debol et al. [43]. Suda et al. utilized human PMN, stimulated by FLMP, C5a and PMA and evaluated any influence of dapsone on the generation 

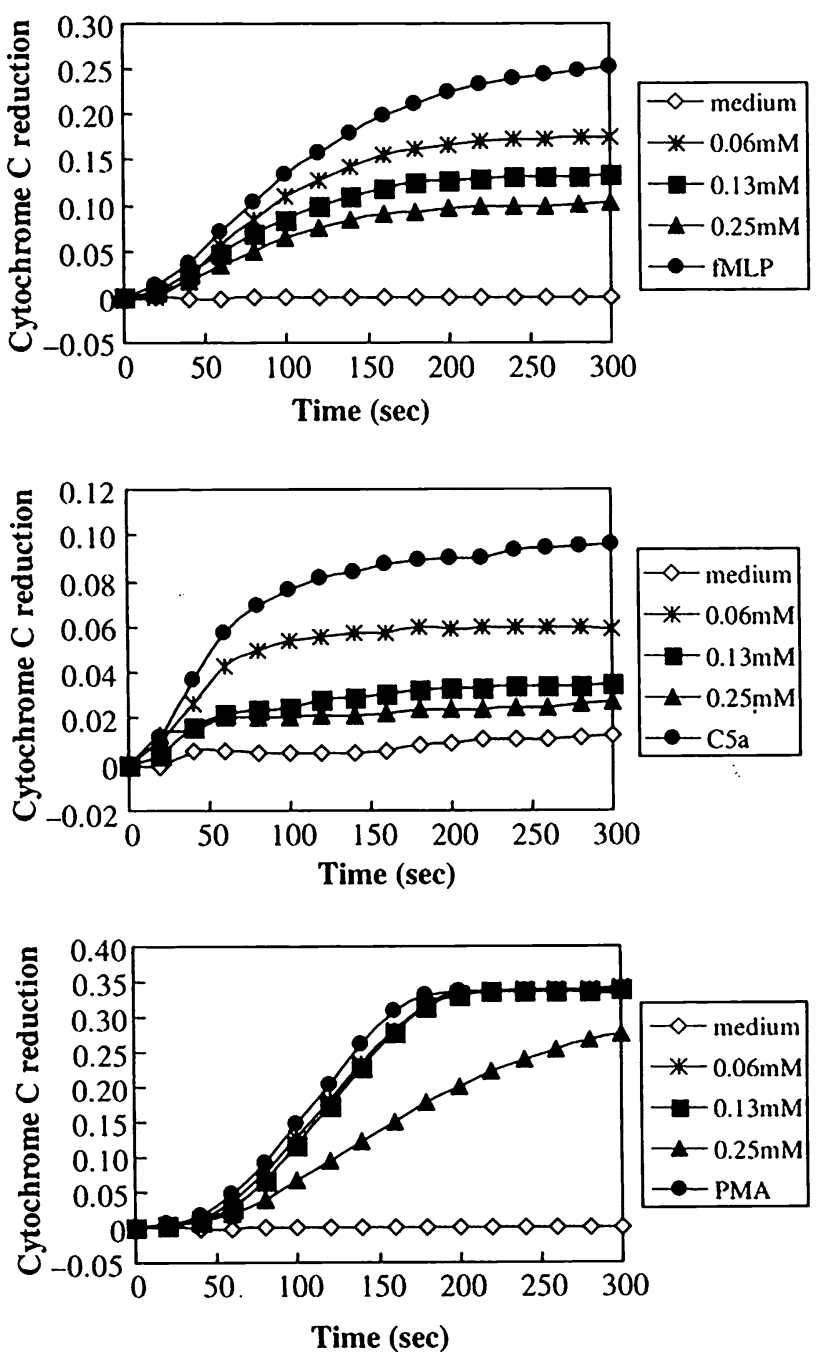

Fig. 4 The effect of dapsone on the extracellular superoxide $\left(\mathrm{O}_{2}{ }^{-}\right)$ release induced by $N$-formyl-L-methionyl-L-leucyl-L-phenyalanine (fMLP), C5a and phorbol myristate acetate (PMA). Neutrophils $\left(1 \times 10^{6}\right.$ cells $\left.\mathrm{mL}^{-1}\right)$ were preincubated with or without dapsone at the concentrations indicated for $30 \mathrm{~min}$ and then stimulated with fMLP $\left(1 \mu \mathrm{mol} \mathrm{L}{ }^{-1}\right) \quad$ (a), C5a $\left(100 \mathrm{nmol} \mathrm{L}^{-1}\right) \quad$ (b) or PMA $\left(100 \mathrm{nmol} \mathrm{L}^{-1}\right)(\mathbf{c})$. After addition of cytochrome $\mathrm{C}\left(20 \mu \mathrm{mol} \mathrm{L}{ }^{-1}\right)$, the reduction of absorbance at $550 \mathrm{~nm}$ in the absence $\left(\Delta \mathrm{OD}_{550}[\mathrm{SOD}]\right)$ was measured for $5 \mathrm{~min}$ using a single-beam spectrophotometer. SOD-inhibitable cytochrome $\mathrm{C}$ reduction corresponded to $\Delta \mathrm{OD}_{550^{-}}$ $\Delta \mathrm{OD}_{550}[\mathrm{SOD}]$. The data shown are representative of three to four separate experiments with similar results. Dapsone suppressed the extracellular $\mathrm{O}_{2}^{-}$production induced by fMLP and C5a but not by PMA. (according to Suda et al. [148])

of extracellular $\mathrm{O}_{2}{ }^{-}$(using a cytochrome $\mathrm{C}$ reductase assay), intracellular $\mathrm{O}_{2}^{-}$(using flow cytometry), the generation of elastase and on cytosolic free ionized calcium. They found dapsone to cause dose-dependant, sizeable reductions of intracellular $\mathrm{O}_{2}^{-}$(after induction by FLMP and $\mathrm{C} 5 \mathrm{a}$ ) and of extracellular $\mathrm{O}_{2}{ }^{-}$(Fig. $4 \mathrm{a}-\mathrm{c}$ ). Stikingly, in these experiments, dapsone appeared to exert little or no effect on PMA-stimulated $\mathrm{O}_{2}{ }^{-}$production. The authors demonstrated an influx of calcium into cells in response to

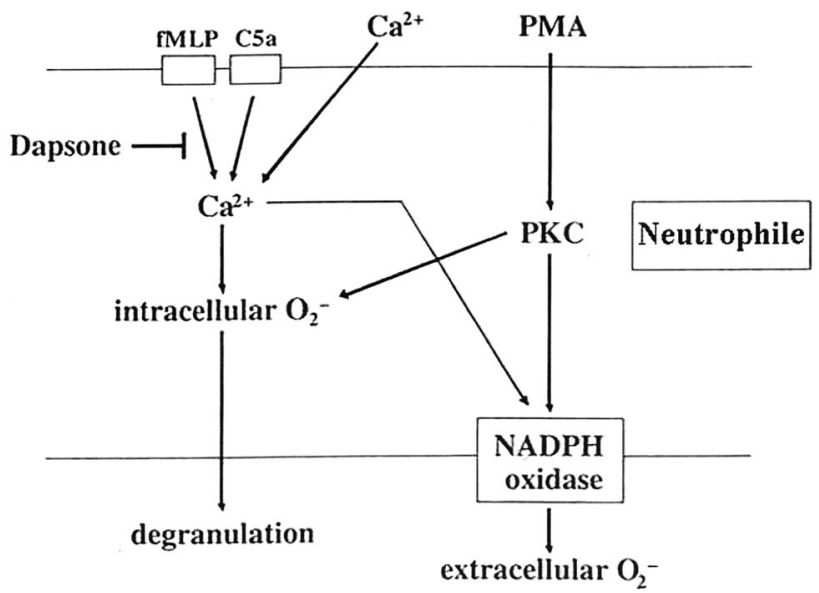

Fig. 5 The effect of dapsone on neutrophils. Dapsone suppressed intra- and extracellular production of superoxide $\left(\mathrm{O}_{2}{ }^{-}\right)$and elastase release triggered by FLMP and physiological agonist C5a, but not by PMA. Both FMLP and C5a signaled the above pathways by inducing calcium influx, but PMA functions bypassed calcium influx. Dapsone was capable of antagonizing the induction of calcium influx (FMLP: $N$-formyl-L-methionyl-L-leucyl-L-phenyalanine, $P M A$ phorbol myristate acetate, $P K C$ protein kinase $\mathrm{C}, N A D P H$ Nicotinamide adenosine dinucleotide phosphate) (according to Suda et al. [148]

FLMP. In contrast, PMA failed to mobilize calcium. Dapsone was seen to inhibit calcium influx in response to FLMP or C5a. Similarly, dapsone was able to inhibit any generation of elastase in the presence of FLMP and C5a. Given that PMA failed to cause an influx of calcium, one may conclude that dapsone exerts some direct effect on the intracellular concentrations of free ionized calcium when the latter was induced by signalling mechanisms [148]. With respect to the $\mathrm{O}_{2}^{-}$production and the effects of dapsone in PMN the authors suggested a pathway which is shown in Fig. 5. The FLMP-induced calcium influx in PMN and its suppression by dapsone were confirmed by other laboratories [43].

The role of dapsone in the generation of reactive oxygen species (ROS) has also been studied in non-phagocytizing cells [27]. These authors utilized diploid fibroblasts obtained from human newborns. The cells were stimulated by paraquat, a herbicide. Paraquat is a known inducer of oxidative stress. Its effect involves the membrane-bound NADPH oxidase and the production of superoxide anion. The intracellular mitochondrial complex may also participate in this process. In the experiments, dapsone-applied in different concentrations-leads to a reduction of the expression of NADPH oxidase 4. Cho et al. [27] found an inhibition of paraquat-inducible proteinkinase $\mathrm{C}$, of the mitochondrial complex, and they showed a reduced production of cytosolic and mitochondrial superoxide anion. Moreover, they showed that dapsone as parent compound does not possess a scavenger function for ROS. In summary, results of these studies repeatedly disclosed that 
dapsone possesses substantial antioxidative properties that can be attributed in large parts to an inhibition of ROS production. This calls earlier studies into question that had ascribed dapsone with direct scavenger function [169]. Apart from this, this experimental study shows for the first time that experimentally stimulated cells without phagocytic properties are capable of producing ROS. In another experiment, the same group examined the mitochondrial complex V of Caenorhabditis elegans (C. elegans) and detected a drop in protein levels in dapsone-treated animals. Again, dapsone inhibited paraquat-induced release of $\mathrm{H}_{2} \mathrm{O}_{2}$. Finally, the authors could reproduce the same effect in mammalian muscle cells (male $\mathrm{BALB} / \mathrm{c}$ mice and C2C12 cells) [26]. These findings confirmed that not only stimulated inflammatory cells can generate ROS that are being down regulated by dapsone.

\section{Myeloperoxidase/halide system}

\section{MPO mediates the transformation of $\mathrm{H}_{2} \mathrm{O}_{2}$ via halogenation}

$$
\mathrm{H}_{2} \mathrm{O}_{2}+\mathrm{Cl}^{-} \stackrel{\text { myeloperoxidase }}{\longrightarrow} \mathrm{H}_{2} \mathrm{O}+\mathrm{ClO}^{-}
$$

In a further reaction, $\mathrm{ClO}^{-}$and $\mathrm{H}_{2} \mathrm{O}_{2}$ can produce the release of singlet- $\mathrm{O}_{2}$ and thereby amplify the cytotoxic potential. It has been generally agreed that part of the antiinflammatory activity of dapsone results from a (reversible) inhibition of MPO. This leads to an inhibition of the conversion of $\mathrm{H}_{2} \mathrm{O}_{2}$ to HOCL. Early works on the mechanisms of action had already postulated a direct inhibition of MPO by dapsone [144, 161]. Subsequent studies have confirmed the inhibitory effect of dapsone on MPO [19, 88, 92, 93, 157]. It is assumed that dapsone exerts a direct inhibition of MPO which leads to the formation of inactive intermediates of the enzyme. As hypochlorous acid is an integral part not only of the antibacterial/antiprotozoal armamentarium of PMN and eosinophils but can also cause tissue damage in non-infectious disease states [163], the inhibition of MPO by dapsone might account for the anti-inflammatory potential of the sulfone.

\section{Adhesion molecules/cellular adhesion}

Leukocyte function antigen (LFA-1) (CD 11 a/CD 18), Mac-1 (CD 11b/CD 18) and p 150, 95 (CD $11 \mathrm{c} / \mathrm{CD} 18)$ are important members of the $\beta_{2}$-integrin family of adhesion molecules. The effects of dapsone on Mac-1-mediated adherence of neutrophils of healthy persons were examined by Booth et al. [16]. They observed a dose-dependent inhibition of adherence, but only when cells were stimulated with either FMLP or PMA. Adherence of unstimulated cells remained unchanged under the influence of dapsone. Addition of integrin- $\beta_{2}$-antibodies proved that adherence was indeed integrin-mediated. Yet it is not clear whether these findings are of relevance in patients treated with dapsone as the concentrations used exceed those under therapy by a factor of 10-100. Heidenbluth et al. [unpublished data] confirmed the ability of dapsone to interfere with the function of integrins. They examined the expression of leukocyte integrins LFA1, Mac-1 and p 150, 95 in various cell populations under the influence of dapsone (20, 100 and $200 \mu \mathrm{g} / \mathrm{mL})$. Fluorescence-activated cell sorter (FACS) analysis was performed in human whole blood, in isolated PMN and in the macrophage cell line U937. Stimulation with PMA induced an increased expression of CD11 a, b, c and CD18 both in PMN and in U937 cells. Dapsone inhibited the expression of $\beta 2$-integrins CD11a, CD11c and CD18 in PMN only marginally, but significantly in U937-cells (CD11c). This effect was not dose dependent. Thuong-Nguyen et al. [151] showed that dapsone inhibited adherence of neutrophils to $\operatorname{IgA}$ and IgG from sera of patients with IgA-linear dermatosis and bullous pemphigoid in a dose-dependent manner. Other investigators established an inhibition of adhesion of TNF$\alpha$ - or platelet activating factor (PAF)-activated PMN of healthy donors by dapsone [116]. This group used a frozen section adhesion assay of healthy skin under incubation with IFN- $\gamma$ and observed an inhibition of neutrophil adhesion to epidermal cells in a concentration range from 0.1 to $80 \mu \mathrm{g} / \mathrm{mL}$ dapsone. They could also verify that dapsone down regulates the expression of CD11b on activated neutrophils.

\section{$\alpha$-1-Protease inhibitor}

In vitro, dapsone possesses a protective effect on elastase inhibitor capacity of $\alpha$-1-protease inhibitor (AIP), thereby showing similar properties as the physiologic antioxidant ceruloplasmine. Once more, this AIP-protective effect has been linked to the potent suppression of ROS-production and to the inhibition of the MPO-halide-system [149]. As the dapsone concentrations used in this study resemble that attained in vivo, this action might be useful in the therapy of diseases with AIP dysfunction.

\section{Chemotaxis}

The impact of dapsone on chemotaxis has been studied with partly conflicting results. A pilot study utilized various chemotaxins and found a selective inhibition by dapsone in concentrations resembling those under therapy only when FMLP was used as stimulus, but not when leukocytederived chemotactic factor (LDCT) and C5a were applied [72]. Moreover, species- and cell dependency could be 
observed; PMN of guinea pigs and monocytes did not show inhibition of chemotaxis. Booth et al. [16] examined chemotaxis and random migration by agarose-technique using FMLP and IL-8 as stimuli. Dapsone was added in concentrations of 30,100 and $300 \mu \mathrm{g} / \mathrm{mL}$. Again, a dosedependent inhibitory effect of dapsone on chemotaxis of human neutrophils could be observed (FMLP: $30 \mu \mathrm{g}$ dapsone/mL: $24 \%$ inhibition, $300 \mu \mathrm{g}$ dapsone/mL: $62 \%$ inhibition, IL-8: $100 \mu \mathrm{g}$ dapsone/mL: $24 \%$ inhibition, $300 \mu \mathrm{g}$ dapsone/mL: $61 \%$ inhibition). Once more, random migration was also inhibited by dapsone. In vivo studies produced inconsistent results. A short-term study with rabbits and guinea pigs which were fed dapsone for 3 days showed no influence of dapsone on chemotaxis of PMN [131]. A1h E. coli activated autologous serum even showed that dapsone induces an increase in chemotaxis in healthy individuals and in leprosy patients [6]. In a human in vivo study in healthy volunteers, leukotriene $\mathrm{B}_{4}\left(\mathrm{LTB}_{4}\right)$ was applied epidermally to induce chemotaxis as described by Lammers et al. [100]. In this setting, Salomon demonstrated that $100 \mathrm{mg}$ dapsone/day does not inhibit $\mathrm{LTB}_{4}{ }^{-}$ induced chemotaxis [135]. This is in consistency with earlier findings that dapsone therapy does not induce inhibition of $\mathrm{LTB}_{4}$-induced chemotaxis in the skin of patients with acne [Prendiville et al., unpublished data]. Further studies with differentially activated sera again came to nothing $[54,55,110,131]$. In conclusion, dapsone inhibits chemotaxis, but only when certain stimuli are applied. Thus, the statement that dapsone inhibits chemotaxis per se can no longer be sustained.

\section{Membrane-associated phospholipid metabolism}

Cell activation produces a process of enzymatically mediated signal transduction which leads to liberation of arachidonic acid which on her part is source of biologically active mediators of the cyclooxygenase (COX)- and lipoxygenase (LOX) pathway. The influence of dapsone on choline phosphotransferase (ChPhTF) and methyltransferase I and II (MTF) was examined using PMN, lymphocytes and erythrocytes of healthy donors [122]. The investigators found a cell-specific inhibitory effect of dapsone. MTFactivity in lymphocytes and PMN was inhibited slightly by high dapsone concentrations, but not that of erythrocytes. Conversely, erythrocytes showed a significant drop of ChPhTF-activity in contrast to PMN and lymphocytes where there was no significant influence. Venom-induced inflammation following the bite of the brown recluse spider (loxosceles reclusa) has been linked to an activation of membrane phospholipids. The venom incorporates a variety of enzymes (e.g. phospholipase D, esterases, and hyaluronidase) that are believed to provoke cutaneous and even systemic effects (viscero-cutaneous loxoscelism).
Using a model of cultivated human keratinocytes, venominduced activation of membrane phospholipids could be confirmed [45]. Whether the well-known therapeutic efficacy of dapsone in the therapy of brown recluse spider bites can be attributed to the aforementioned mechanism remains speculative [165].

\section{Prostaglandins}

Regarding the inhibition of synthesis and liberation of prostaglandins by dapsone, there is some evidence presented by Ruzicka et al. [134]. Using thin layer chromatography, the authors examined the production of prostaglandin $\mathrm{D}_{2}\left(\mathrm{PGD}_{2}\right)$ of mast cells that had been gathered from the plasma and peritoneal caves of SpragueDawley rats under the influence of dapsone $\left(10^{-2}\right.$ $\left.10^{-6} \mathrm{~mol} / \mathrm{L}\right)$. Their experiments revealed a dose-dependent inhibition of the production of $\mathrm{PGD}_{2}\left(\mathrm{IC}_{50}\right.$ : $1 \mathrm{mmol}$ with exogenous arachidonic acid (AA)-application, 0.2-0.4 mmol with exclusively endogenous AA). Complete suppression was observed with $6 \times 10^{-3} \mathrm{~mol}$ or $6 \times 10^{-2}$ mol, respectively. Washing the cells following incubation with dapsone completely abolished this effect pointing to a reversible effect. Moreover, dapsone had a marked inhibitory effect on IgE-mediated antigen-stimulated production of $\mathrm{PGD}_{2}$ (IC50: $0.2-0.4 \mathrm{mmol}$ ). Interestingly, the liberation of histamine was not inhibited. As the conversion of $\mathrm{PGH}_{2}$ to $\mathrm{PGD}_{2}$ was not influenced by dapsone, the target of dapsone can be assumed to be located before the PGH-PGD-isomerase step. The authors postulate a direct inhibitory effect on COX. A similar dose-dependent inhibitory effect of dapsone on the production of $\mathrm{PGD}_{2}$ and 6-keto prostaglandin $\mathrm{F}_{1} \alpha\left(6 \mathrm{KF}_{1} \alpha\right)$ by peritoneal macrophages of mice was described by Bonney et al. [15]. Apart from mast cells and macrophages, human PMN were examined in respect to a possible inhibition of the COX pathway [6]. In contrast to clofazimine, dapsone in concentrations of 5 and $10 \mu \mathrm{g} / \mathrm{mL}$ inhibited both spontaneous and FMLP-induced synthesis of $\mathrm{PGE}_{2}$. There was no difference between the PMN of healthy donors and of leprosy patients. In summary, the inhibitory effect of dapsone on prostaglandin synthesis/liberation is beyond doubt.

\section{Leukotrienes}

Dapsone is capable of inhibiting the generation of 5-LOXproducts in PMN of healthy donors [171]. PMN were pretreated with dapsone in different concentrations (1.6-100 $\mu \mathrm{mol})$ subsequently by adding $\mathrm{Ca}$ ionophore A 23187 and subsequent incubation. Thereupon, the eicosanoids were assessed by reversed-phase high-performance liquid chromatography (RP-HPLC). Dapsone exhibited dose-dependent inhibitory activity showing $50 \%$ 
inhibition at $15 \mu \mathrm{mol}$ for $\mathrm{LTB}_{4}$ with $5 \times 10^{6}$. The $\mathrm{IC}_{50}$ of dapsone for 5-hydroxyeicosatetraenoic acid (5-HETE) and $\omega$-OH-LTB ${ }_{4}$ amounted to similar values (5-HETE: $9 \mu \mathrm{mol}$; $\omega$-OH-LTB 4 : $11 \mu \mathrm{mol})$. In additional experiments, cells were destroyed with ultrasound and the supernatant incubated with dapsone $(1.6-100 \mu \mathrm{mol})$ under the addition of AA. Table 2 depicts the $\mathrm{IC}_{50}$ calculated for $\mathrm{LTB}_{4}$ and 5-HETE in intact PMN and in the cell-free system. The variations indicate that dapsone also inhibits enzymatic systems beyond 5-LOX. As subsequent studies demonstrated, this might be attributed to calcium mobilization [148]. In rat mast cells, dapsone had a similar inhibitory effect on 5-LOX [134]. Maloff et al. [107] examined the effect of dapsone on $\mathrm{LTB}_{4}$-receptors. Using human PMN, they could demonstrate that dapsone in concentrations of 10,50 and $100 \mu \mathrm{mol}$ inhibits the specific binding of $\mathrm{LTB}_{4}$ to the receptor. A further increase of dapsone concentrations did not result in an increase of the blockade. The exact mechanism of the interruption of the ligand-receptor signal cascade is not known. In respect to an inhibition of cysteinyl leukotrienes Bonney et al. [15] examined peritoneal macrophages of male Swiss-Webster mice. Stimulation with zymosan led to a time- and dose-dependent synthesis of leukotrienes and prostaglandins. When dapsone was added in concentrations of 50, 100 and $200 \mu \mathrm{g} /$ $\mathrm{mL}$, this caused a dose-dependent suppression of $\mathrm{LTC}_{4}$ synthesis. The other two peptido-leukotrienes were not examined. The inhibitory effect of dapsone on $\mathrm{LTC}_{4}$ production could account for the observation that dapsone possesses corticosteroide-sparing effects in asthma patients For instance, Berlow et al. [10] could verify that adjuvant therapy with dapsone $(2 \times 100 \mathrm{mg} /$ day $)$ reduced the monthly prednisolone dose from 428 to $82 \mathrm{mg}(p<0.2)$ in patients with chronic, cortisone-dependent asthma. Again, the exact mechanism of this cortisone-sparing effect is not known.

\section{Interleukin 8}

Interleukin 8 (IL-8), a member of the CXC-chemokine family, purportedly plays an important role, especially in neutrophil-mediated inflammation, but has also been

Table $2 \mathrm{IC}_{50}$ of dapsone for $\mathrm{LTB}_{4}$ and 5-HETE in a cell-free system (5-LOX) and in intact PMN

\begin{tabular}{llc}
\hline $\mathrm{IC}_{50}(\mu \mathrm{M})$ & & \\
\hline & $\begin{array}{l}\text { Cell free }(5-\mathrm{LOX}) \\
\left(5 \times 10^{6} \mathrm{PMN}\right)\end{array}$ & $\begin{array}{l}\text { Intakt PMN } \\
\left(5 \times 10^{6} \mathrm{PMN}\right)\end{array}$ \\
\hline $\mathrm{LTB}_{4}$ & $35.0 \pm 4.3$ & $15.0 \pm 5.6$ \\
5 -HETE & $59.0 \pm 5.1$ & $9.0 \pm 7.1$ \\
\hline
\end{tabular}

Data represent the mean \pm SEM of at least three separate experiments shown to affect other cell species as well (e.g. lymphocytes, monocytes, hematopoietic progenitor cells). Signal transduction is mediated via CXCR 1 and CXCR2 receptors and is involved in viral infections and tumor progression [117]. Following observations that ROS markedly influence the regulation of IL-8 [44] studies were initiated that examined the effect of dapsone on IL 8 in different settings $[44,80]$. In an in vitro model of human whole blood, dapsone in therapeutic concentrations was shown to exert a suppressive effect on lipopolysaccharide (LPS)- induced IL-8 levels [13], an observation that was confirmed by several study groups. Amongst others, dapsone suppresses bullous-pemphigoid-IgG-induced IL-8-release from keratinocytes at a posttranscriptional level [139] and is capable of inhibiting IL-8-mRNA expression [1]. Accordingly, dapsone blocks IL-8-induced chemotaxis [16, 65]. Furthermore, IL- 8 has been shown to be of importance in neurologic diseases. It is expressed by neurons [174] and glioblastoma cells have been shown to be affluent sources of IL-8 [96]. As dapsone shows a suppressive effect on seizure disorders [103] and inhibits the growth of glioblastoma, it is discussed that these effects might be mediated by an inhibitory effect on IL-8 via targeting neutrophils [85]. Lately, the therapeutic application of dapsone in glioblastoma was the object of several studies [85]. However, with the advent of modern molecular-targeted strategies like inhibition of epidermal growth factor receptor, vascular endothelial growth factor, mammalian target of rapamycin (mTOR) and others, the value of dapsone in this field remains doubtful.

\section{TNF- $\alpha$}

Abe et al. [1] examined the influence of dapsone on TNF- $\alpha$ and other proinflammatory cytokines like IL- $1 \beta$ - and IL-8 in the context of its therapeutic use in lupus erythematosus. This group used PBMC from healthy donors which were stimulated with LPS. Dapsone induced a dose-dependent suppression of TNF- $\alpha$ at mRNA level. With the exception of IL-8, no influence on the levels of other cytokines was found. The effect on IL- 8 resembled to that already reported above. It has to be pointed out, however, that the dapsone concentrations used in this study exceed that under therapy.

\section{Eosinophil peroxidase}

In comparison to the effect on neutrophils, those on eosinophils have been far less studied. It is likely that overlapping mechanism play a role (e.g. inhibition of lipoxygenase, ROS production). Bozmen et al. examined the influence of dapsone on eosinophil peroxidase [19]. The inhibitory effect of the sulfone on MPO was even 
stronger than that in neutrophils and associated with a reduced production of toxic hypochlorous acid and other ROS. Consecutively, the effect of eosinophil peroxidase on mast cells was reduced (e.g. liberation of histamine) [142]. The inhibitory effect on eosinophil peroxidase could provide at least in part an explanation of the therapeutic efficacy of dapsone in eosinophil-mediated diseases (e.g. eosinophilic fasciitis).

Complement system, coagulation and fibrinolytic system, cutaneous proteases

In vitro, an inhibitory effect of dapsone on the alternative way of complement activation was detected [Millikan et al., unpublished data]. On the contrary, Katz et al. could not find an influence of dapsone on the classic or alternative activation of complement in patients with dermatitis herpetiformis and in animal experiments [87]. Anecdotal reports document a normalization of initially decreased complement factors in immune complex vasculitis under therapy with dapsone $[132,167]$. Certainly, these effects could be the result of an improvement of the disease per se and not necessarily be a result of a specific effect of dapsone on complement factors. Dapsone had no influence on plasminogen activator when epidermal cells were incubated with pemphigus antibodies [73]. Finally, the effect of dapsone on cutaneous proteases was found to be only minor [60].

\section{Lymphocyte function}

Once more, results with regard to lymphocyte function are in part contradictory. Beiguelman and Pisam [9] described an inhibition of PHA-induced lymphocyte-transformation (LZT) by dapsone. In healthy donors who had taken dapsone in therapeutic doses for 7 days, a significant inhibition of PHA-stimulated LZT could be observed [140]. Other authors could confirm this observation when using other mitogens like concanavalin A and lepromin [5, 99]. The influence of dapsone on delayed type hypersensitivity was examined in a mouse model by Nagata et al. [119]. A daily clinical dose (1CD) of dapsone taken to be equivalent to that used in humans was $1.7 \mathrm{ng} / \mathrm{kg}$ of body weight. Up to threefold equivalent doses of dapsone (3CD) exerted no reduction of carrageenan-induced paw edema. On the other hand in mice alimentation with dapsone was followed by an emptying of the paracortical zone of lymph nodes [99]. Interestingly, dapsone loses its antibacterial potency against inoculated mycobacterium (M. leprae) in thymectomized naked mice, in contrast to mice with normal immune system [119]. In comparison with T-lymphocytes, B-lymphocytes are influenced by dapsone to a far lesser extent. In 20 patients with lepra lepromatosa who were treated with dapsone $50 \mathrm{mg} /$ day over 12-24 months, there was no difference in the number of B-lymphocytes when compared with 26 untreated leprosy patients and 25 healthy controls [99]. Dapsone did not influence antibody-producing cells of BALB/c- and C57 BI/6-mice in a plaqueforming cell assay [119]. Furthermore, Thompson and Souhami could not find any changes in antibody production [150]. In contrast to that, Das et al. 1985 [unpublished data] demonstrated a dose-dependent inhibition of the synthesis of rabies-specific IgA- and IgG-antibodies by dapsone. The production of total $\operatorname{IgA}$ and $\mathrm{IgG}$ was not influenced. The authors attribute the inhibitory effect on specific B cell clones to a reduction of antigen-specific $\mathrm{T}$-helper cell activity. The action of dapsone on Arthus reaction is controversial. Thompson and Souhami [150] as well as Ruzicka et al. [131] observed a dose-dependent suppressive effect of dapsone in guinea pigs and rabbits. Sulfoxone, a soluble sulfone, exerted no effect in guinea pigs with $\mathrm{C} 4$ deficiency [87].

Animal studies with liver and spleen immune cells (Tand B-lymphocytes stimulated with concanavalin A and LPS) revealed a dose-dependent effect of dapsone. At lower concentrations $(1 \mu \mathrm{mol})$, dapsone stimulated B- and $\mathrm{T}$-cell proliferation under the influence of both mitogens, but inhibited B-cell proliferation at higher concentrations (150 $\mu \mathrm{mol})$. The authors claim an immunostimulating effect of dapsone in lower concentrations but an immunosuppressive in higher concentrations as general principle [90].

\section{Lifespan of Caenorhabditis elegans}

In the light of observations that-despite their diseaseinduced socioeconomic drawbacks-life expectancy of leprosy patients under dapsone therapy is increased, South Korean authors investigated the effect of dapsone on the lifespan in multicellular organism [26]. In their anti-agingmodel, dapsone in concentrations equalling that achieved under therapy induced a marked elongation of the median lifespan of Caenorhabditis elegans (Fig. 6). The nematode worm is a small, relatively simple, and precisely structured organism. C. elegans is one of the most powerful animal models currently in use for studying the aging process and lifespan.

Dapsone delayed the induction of aging and was shown to suppress mitochondrial ROS as well as mRNA of NADPH-oxidase. Typical scavenger-enzymes like superoxide dismutase (SOD), catalase, glutathione peroxidase-/ reductase were not influenced by dapsone. As already noted, this contrasts with earlier studies which had postulated a scavenger function of dapsone. More precisely, dapsone seems to inhibit the production of ROS as it has been shown by molecular studies by Cho et al. [26, 28]. 


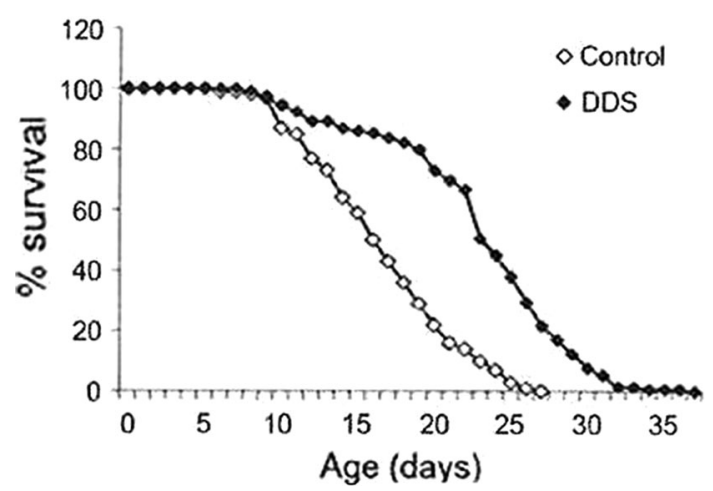

Fig. 6 Survival curves of Ceanorhabditis elegans $(n=129)$ treated with dapsone $(2 \mathrm{mmol})$ during their entire life time compared with worms that were untreated. (according to Cho et al. [26])

Interestingly, these authors have identified muscle pyruvate kinase as the protein target of dapsone in C. elegans. Additional studies in long-term dapsone therapy leprosy patients using a ferric-reducing ability assay demonstrated increased antioxidative capacity in erythrocytes. These mechanisms could be reproduced in mammalian cells [26]. Experimental and clinical results thus confirm studies in human fibroblasts [27].

\section{Neuroprotection}

Recent research revealed that dapsone can influence functions of the central nerve system [86, 120, 129, 130, 160]. More precisely, it could be shown that dapsone suppresses experimentally induced neurotoxicity [138]. In a pilot study, neuroprotective effects of dapsone could be demonstrated in stroke patients. Patients were given a single $200 \mathrm{mg}$-dose of dapsone within $12 \mathrm{~h}$ following the incident. A follow-up study of 60 days' duration showed a significant reduction of National Institute of Health Stroke Scale (NIHSS) in comparison with a placebo group [118]. In order to further clarify the protective mechanism of dapsone, animal ischemia-reperfusion studies supplied evidence that dapsone exerts an inhibitory effect on lipid peroxidation, MPO, nitric oxide activity and apoptosis (annexin V, caspase 3 und 9) [46]. Again, this neuroprotective effect of dapsone was attributed to its antioxidative capacities. Anticonvulsive effects of dapsone have been described in earlier studies [4, 70, 78]. In the context of neurologic diseases, Japanese authors have reported successful therapy of steroiddependent neuro-Sweet-disease that responded to $75 \mathrm{mg}$ dapsone/day [141] (see 4.10). The neuro-Sweet-disease is characterized by multiple neurologic (e.g. meningitis, encephalitis) and well-known dermatological features (e.g. painful dull red erythematous plaques) in association with HLA-Cw1 or B54.
Tumor growth

Following 16 days of inoculation with a continuous sixfold equivalent dose of dapsone, BALB/c-mice-myeloma cells growth showed no difference when compared with animals that had been fed with placebo [119]. In contrast, recent studies generated results pointing to an anti-cancer activity of certain dapsone derivatives [3, 12, 25, 71, 124]. At present, further research in this field is in progress.

Human pharmacology studies

After topical pretreatment with dapsonemetabolites MADDS und DDS-NOH (both $1 \%$ dissolved in acetone) for 2 weeks, $10 \mathrm{ng} \mathrm{LTB}_{4}$ was applied on skin of eight healthy volunteers. Biopsies were taken after $24 \mathrm{~h}$ and PMN were quantified flourometrically using elastase according to the method of Lammers et al. [100]. MADDS did not exert any inhibitory activity on PMN trafficking compared with corresponding controls and untreated area (untreated: $790 \pm 450 \mathrm{PMN}$ per $10 \mu \mathrm{g}$ skin; $\quad p>0.05$, acetone: $840 \pm 578$; MADDS: $1099 \pm 556$ ), whereas DDS-NOH caused a statistical significant inhibition of PMN accumulation even exceeding the effect of the reference clobetasol-17-proprionate (CP) (DDS-NOH: $128 \pm 143$ PMN; CP: $86 \pm 131$ ) [172]. In contrast, the parent compound dapsone did not inhibit $\mathrm{LTB}_{4}$-induced chemotaxis of PMN (see section "Chemotaxis"). These in vivo results clearly demonstrate that dapsone metabolites, especially DDS$\mathrm{NOH}$, are pharmacodynamically active (Blasum et al., unpublished data). This raises the question whether attempts to increase the tolerability of dapsone therapy by trying to decrease the production of DDS-NOH might inevitably be accompanied by a loss of therapeutic efficacy (see below). In a first-proof-of-concept study with healthy volunteers there was some evidence that topical applied dapsone (1\% solved in acetone) per se may have the potential to reduce UV-induced erythema Salomon [135] (Fig. 7). In line with this pilot study are results of experiments with both, dapsone and dapsone metabolites, MADDS and DDS-NOH. [135]. Skin areas were irradiated with UVB (295 nm, two minimal erythema doses). Twenty-four hours later, UVB-induced erythema was quantified and cutaneous blood flow measured using Laser Doppler Imager. In control skin, tissue blood flow was measured to be 227 units and was significantly $(p<0.05)$ decreased by dapsone (186 U), DDH-NOH (154 U), and MADDS (195 U). UVB-induced erythema was also significantly reduced in DDS-NOH- or MADDStreated skin when compared with controls. Thus, these experiments show that dapsone metabolites exert pharmacodynamic effects when applied topically to the skin 


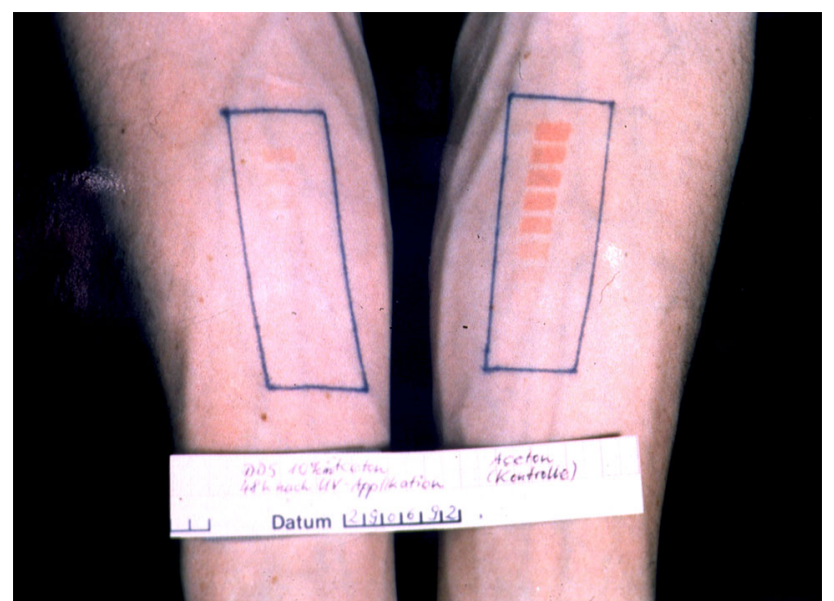

Fig. 7 Suppression of ultraviolet (UV)-induced erythema with topical applied dapsone (1\% solved in acetone, $48 \mathrm{~h}$ after UV exposition) (right forearm), control: left forearm (UV source: UVB erythemal effective Hg-lamp VITALUX/OSRAM GmbH, Germany)

and may at least equal dapsone in their anti-inflammatory properties. UVB erythema-suppressing activity of dapsone was subsequently confirmed by Salomon, who observed significant inhibitory effects of both topically applied $(0.1-10 \%)$ and systemically applied dapsone (100 mg/day) on UV-induced erythema in healthy volunteers having sunreactive skin type II and III. A theoretical explanation for the observed erythema-suppressing effect of dapsone could be the drug's inhibitory action on prostaglandins. In this context, it is noteworthy that dapsone-topically and systemically applied-unexpectedly exerted no substantial effect on anthralin- and sodium dodecylsulfate-induced erythema in healthy volunteers [135]. Dapsone metabolites were not used in these investigations.

In another human pharmacology study, dapsone was found not to possess antipsoriatic efficacy in the psoriasis plaque test [168].

\section{Unique characteristics of dapsone}

The association of antimicrobial/antiprotozoal and antiphlogistic effects in a broad range of indications places dapsone in a unique position in the spectrum of non-steroidal antiphlogistic drugs. Currently, no other drug used in medicine possesses such a wide variety of beneficial properties as follows:

1. Combination of antimicrobial/antiprotozoal effects (utilized, e.g. in the treatment of opportunistic infections in patients with acquired immunodeficiency syndrome).

2. Safety of long-term treatment (e.g., life-long use in leprosy, long-term or chronic intermittent therapy of inflammatory dermatoses).
3. Unique powerful disease-specific antiphlogistic activities (e.g., prompt decrease of pruritus and control of skin lesions in dermatitis herpetiformis; fast amelioration of loxoscelism associated with brown recluse spider bites).

4. Steroid-sparing effects (e.g., long-term treatment in autoimmune blistering diseases and as an adjuvant treatment in bronchial asthma).

5. CNS-protective effects (anticonvulsive effects, reduction of stroke-associated tissue damage, inhibition of glioblastoma).

Finally, the pharmacoeconomic benefit due to the low cost of dapsone deserves to be mentioned.

\section{Adverse effects of dapsone}

Haematology

As already mentioned, hydroxylamines of dapsone, above all DDS-NOH, are held responsible for some of its major adverse effects including met-Hb formation, haemolysis and agranulocytosis. As DDS-NOH is inevitably formed during dapsone therapy, all these adverse effects are obligatory and vary only in intensity. These hematologic side effects of dapsone have long been recognized and have been reviewed by various authors $[11,101,125,136,165$, $173,178]$. Therefore, they will not be dealt with in detail in this survey. However, it has to be stressed that glucose-6phosphate dehydrogenase (G6PD)-deficient patients are less susceptible to met-Hb production, but more susceptible to haemolysis. For instance, patients with G6PD-deficient erythrocytes reveal about a twofold increase in sensitivity towards sulfone-induced anaemia. Cyanosis which is usually associated with mild methaemoglobinemia may occur during dapsone treatment. Acute methaemoglobinemia occurs rarely, but may result in dyspnea, anemia, vascular collapse, and in serious courses finally in death. In patients who do not have G6PD deficiency acute methaemoglobinemia should be treated with intravenous methylene blue (1-2 $\mathrm{mg} / \mathrm{kg}$ given by slow injection). The effect is generally complete within $30 \mathrm{~min}$, but the procedure may need to be readministered if met- $\mathrm{Hb}$ reaccumulates.

\section{Skin}

In respect of dermatological side effects, various skin eruptions have been described [81]. They include exfoliative dermatitis, erythema multiforme, urticaria, erythema nodosum, morbilliform and scarlatiniform exanthema and toxic epidermal necrolysis. Dapsone-induced photosensitivity is quite rare, not dose-dependent and might be caused 
Fig. 8 Photoallergic reaction by dapsone in a female patient with linear IgA dermatosis (a), Photo-patch test $\left(5 \mathrm{~J} / \mathrm{cm}^{2} \mathrm{UVA} /\right.$ Philips TL09) with dapsone and the two main metabolites of dapsone (b), (according to Stöckel et al. [145])

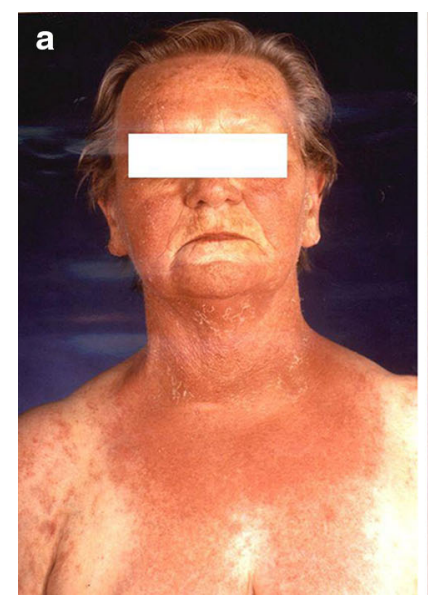

b

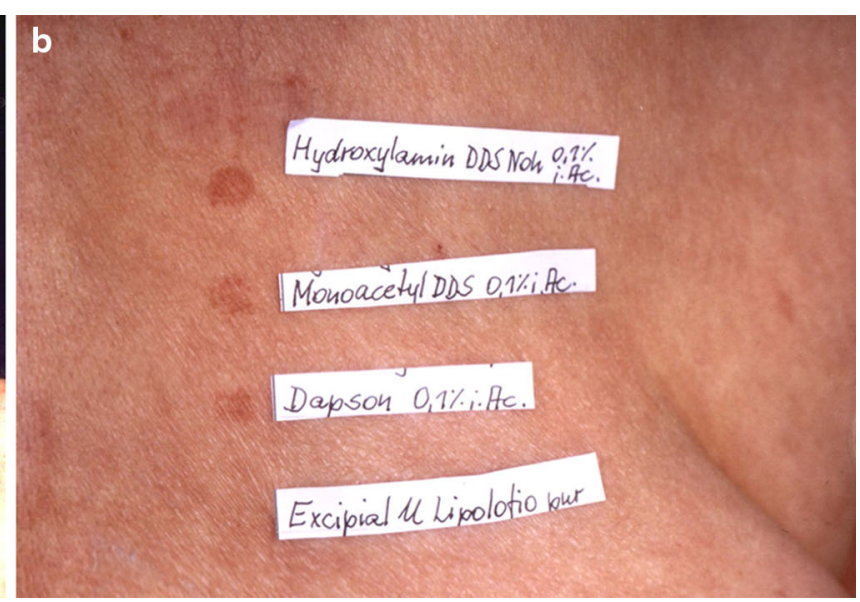

not only by the parent compound dapsone but also by its metabolites (Fig. 8a, b and point 8.4.) [145].

Rash reportedly occurs in about $30-40 \%$ of AIDS patients receiving dapsone concomitantly with trimethoprim, but less frequently in those receiving dapsone alone. Despite that observation, a substantial proportion of patients who do not tolerate co-trimoxazole are able to tolerate dapsone [41].

\section{Nervous system}

Rarely, peripheral neuropathy with primarily motor function loss has been reported in patients receiving dapsone. Recovery might occur; however, this may take many months to several years. Tragic cases of patients who had ingested dapsone with suicidal intention confirm the ability of the drug to damage the peripheral nervous system, including the optic nerve resulting in blindness [77, 91]. In any case, if any signs of neuropathy show, therapy with dapsone should be immediately stopped (Figs. 9, 10, 11).

\section{Gastrointestinal effects/hepatic reactions}

Adverse Gastrointestinal (GI) effects including anorexia, abdominal pain, nausea and vomiting can be encountered in patients receiving dapsone. Due to their potential severity, hepatic adverse effects deserve special attention. There are three types of reactions:

1. Isolated abnormalities of liver function tests (e.g., increased bilirubin and/or liver enzymes) without evidence of hepatitis or hepatosis. If any abnormality is detected, the dosage of dapsone should be decreased or the drug should be discontinued until the source is established.

2. Prehepatic jaundice induced by haemolytic anaemia. Hyperbilirubinemia may occur more often in patients with G6PD-deficiency. All affected patients should be

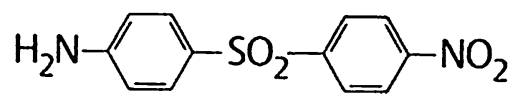

Fig. 9 Chemical structure of dapsone hydroxylamine

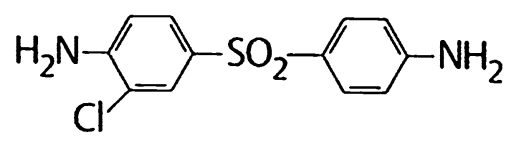

Fig. 10 Chemical structure of chlorodapsone

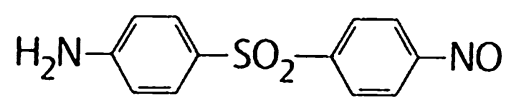

Fig. 11 Chemical structure of a nitroderivative of dapsone

monitored periodically after reduction of dapsone dosage/discontinuation of treatment.

3. Toxic or cholestatic hepatitis in conjunction with hypersensitivity syndrome (HS). Hepatic coma is indeed the most frequent cause of death in the hypersensitivity syndrome [104].

\section{Hypersensitivity syndrome}

The most recent study on HS was published in 2012. This review analyzed all published cases from 1951 (the beginning of the sulfone area) up to 2009 [104]. Of 492 reports, 114 (17 epidemiologic studies and 97 case reports) met the criteria to be included in this metaanalysis. All in all, the cases of 336 patients with HS were analyzed. Prevalence was calculated as $1.4 \%$ (95\% confidence interval: $1.2-1.7 \%)$. Latency of HS after initiation of dapsone treatment was $\leq 20$ days: $24.5 \%$; $21-28$ days: $35.0 \%$; 29-35 days: $20.9 \%$; $\geq 36$ days: $19.6 \%$. Maximum latency was 20 weeks. Nearly all patients presented with a rash $(91.1 \%)$ and fever $(96.9 \%) ; 73.7 \%$ showed 
lymphadenopathy. Hepatic dysfunction could be detected in the majority of cases, its severity ranging from abnormal liver tests over hepatosplenomegaly and jaundice to hepatic coma. About half of the patients demonstrated haematologic changes (leukocytosis $56.6 \%$, eosinophilia $43.8 \%$ ). Relevant clinical features of HS are summarized in Table 3. Following withdrawal of dapsone (and in most cases therapy with steroids), the majority of patients $(82.3 \%)$ recovered, but nearly $10 \%$ had fatal outcome, hepatic coma being the most frequent cause of death. As expected, early discontinuation of dapsone was associated with a better prognosis. On the other hand, mucosal involvement, hepatitis, older age and concomitant diseases which occurred predominantly in third-world countries were all associated with a higher risk of fatal outcome. Considering the widespread use of dapsone and the paucity of reports, and in line with this results of the metaanalysis HS to dapsone is not a rare adverse effect. It occurs in more than $1 \%$ of all cases [104].

Some other adverse effects of dapsone with hitherto unknown mechanisms have been recognized. Fortunately, most of them are really extremely rare (e.g. albuminuria, insomnia, psychosis, changes of electrolytes,

Table 3 Clinical features of hypersensitivity reaction of dapsone (HS)

\begin{tabular}{lrl}
\hline & $n$ Total $(n-334)$ & $\%$ \\
\hline Latency (days) & & \\
$\leq 20$ & 40 & 24.5 \\
$21 \leq 28$ & 57 & 35.0 \\
$29 \leq 35$ & 34 & 20.9 \\
$\geq 36$ & 32 & 19.6 \\
Complete HS & \\
Fever & 149 & 61.1 \\
Lymphadenopathy & 277 & 96.9 \\
Hepatitis & 196 & 73.7 \\
Skin symptoms & 239 & 81.0 \\
Exanthema/erythema & 274 & 91.9 \\
Erythroderma & 155 & 57.4 \\
Rash & 36 & 13.3 \\
Mycosal involvement & 79 & 29.3 \\
Concomitant symptoms & 53 & 42.1 \\
Leukocytosis & 149 & 89.02 \\
Anaemia & 79 & 56.6 \\
Eosiniphilia & 102 & 55.7 \\
Dapsone cessatione & 78 & 43.8 \\
Immediately after HS onset & 85 & 33.9 \\
Delayed to HS onset & 48 & 19.1 \\
Timepoint unspecified & 167 & 47.0 \\
Systemic steroid therapy & & 82.3 \\
\hline Presence ofl four car &
\end{tabular}

${ }^{a}$ Presence of all four cardinal symptoms atrioventricular block) [41, 165, 177]. Some of these may be partially attributed to anaemia and/or methaemoglobinaemia.

\section{Clinical use of dapsone}

\section{Indications}

Due to its antimycobacterial effects, dapsone is a component of rifampicin-based multiple drug regimes for the treatment of multibacillar and paucibacillary leprosy. Besides rifampicin, the WHO most notably recommends combinations with clofazimine [41, 67]. The antiprotozoal effect of dapsone is used in primary prophylaxis and prevention of recurrence in AIDS patients with pneumocystis jiroveci pneumonia and toxoplasmosis.

As anti-inflammatory agent, dapsone is employed primarily to treat chronic skin diseases characterized by an accumulation of neutrophils and/or eosinophils (Table 4). During the past years, dapsone has been introduced additionally into the therapy of several other dermatoses, mostly in combination with other drugs, namely topical or systemic steroids (Table 5). In the literature there is a huge number of case reports, clinical studies and epidemiological analyses representing beneficial effects of dapsone in such dermatological entities, collectively termed as sulfone-sensitives dermatoses. Despite a large body of evidence the subsequent enumeration is indicating only a small number of relevant references $[21,30,31,56,62,65$, 68, 74, 82-84, 98, 126, 133, 143, 153, 164, 175, 179]. Finally, there are some conditions in which dapsone was reported anecdotically as being useful, but initial enthusiasm has been tempered with subsequent controversial or contradictory results and/or a total lack of properly controlled trials showing efficacy. At present, the use of dapsone in these entities can thus be advocated only in totally recalcitrant or refractory cases (see review [173]).

In recent years, dapsone has been employed in a variety of non-dermatological diseases. Haar et al. [69] compared the efficacy of dapsone with hydroxychloroquine and a

Table 4 Dapsone as first choice of treatment in chronic inflammatory dermatoses

Acropustulosis infantilis [21, 165]

Dermatitis herpetiformis Duhring [41, 56, 87, 144, 165, 178, 179]

Erythema elevatum et diutinum [65, 164, 165, 178]

IgA pemphigus [84, 178]

Linear IgA dermatosis [39, 101, 145, 151, 164, 178]

Prurigo pigmentosa $[115,165]$

Subcorneal pustular dermatosis Sneddon-Wilkinson [30, 143, 164, $165,178]$ 
Table 5 Dapsone used in dermatologic entities as an adjunctive treatment modality

Brown recluse spider bite (loxoscelism) [164, 165, 178]

Bullous pemphigoid [68, 84, 126, 139, 153, 164, 165, 178]

Chronic-idiopathic urticaria/delayed pressure urticaria ${ }^{\mathrm{a}}$

Cutaneous lupus erythematosus [41, 132, 133, 164, 165, 173]

Eosinophilic folliculitis (Ofuji's disease) [173]

Leukocytoclastic vasculitis/urticaria vasculitis [62, 113, 165]

Lichen ruber pemphigoides [31]

Mucous membrane pemphigoid [74, 98]

Pemphigus vulgaris $[68,83,84,98,165,178]$

Pyoderma gangrenosum [30, 164, 165]

Reccurent neutrophilic dermatosis of the dorsal hands [173]

Relapsing polychondritis [164, 165, 173, 178]

Sweet's syndrome [141, 178]

a There are some case reports reporting a successful treatment of patients with chronic-idiopathic urticaria and delayed pressure urticaria vor [58, 66, 108]. Recently, dapsone was also investigated in retrospective or randomized non-blinded trials [14, 24, 42, 53, 75]. The results are confirming beneficial effects for dapsone. The German S3-guideline for treatment of chronic urticaria, therefore, recommends dapsone amongst cyclosporine, histamine ${ }_{2}$-receptor antagonist, omalizumab and systemics steroids as additional drug of treatment level 4 [180]

combination of both in rheumatoid arthritis (RA). Dapsone was equally potent as the antimalarial. More than 10 studies have since then proved the efficacy of dapsone in RA [165]. Certainly, in the face of the introduction of biologics (e.g. TNF- $\alpha$ antagonists, rituximab and januskinase inhibitors like tofacitinib), the therapeutic armamentarium has been broadened to an extent that leaves dapsone a dark horse in this indication. For eosinophilic fasciitis, there are impressive case reports about the efficacy of dapsone [142]. Dapsone has been used in several clinical studies in patients with immune thrombocytopenia (ITP) in which the disease was refractory against standard therapy [40, 51, 52, 176]. Surprisingly, dapsone showed compelling efficacy both in adults and in children [40]. This has led to a discussion among haematologists whether dapsone should be classified as second-line therapy for patients with ITP. In cortisonedependent asthma bronchiale patients, co-medication with dapsone allowed a reduction of steroid dose. The application of dapsone in glioblastoma and seizures has already been dealt with above (see point 4.16. and Table 6).

With these diseases, dapsone has made its way into the field of non-dermatological disorders. However, many scientific questions have not yet been answered and its definitive status remains to be elucidated.

One topical gel formulation of $5 \%$ dapsone is available on the US market for treating acne vulgaris. Results of two large-scale studies (dapsone: $n=1506$; vehicle: $n=1504$ ) show a marginal to moderate reduction of noninflammatory lesions compared with placebo after a
Table 6 Dapsone used in non-dermatological diseases

Rheumatoid arthritis
Eosinophilic fasciitis
Immune thrombocytopenia
Stroke
Asthma bronchiale
Seizure disorder
Glioblastoma

12-week treatment period (mean change: $32 \%$ dapsone vs $42 \%$ vehicle) [48]. For treatment of acne in adults, adolescents and children 12 years of age or older, a thin layer of dapsone gel should be applied to the cleansed affected areas. Combinations with topical benzoyl peroxide may result in temporary local yellow or orange discoloration of the skin and facial hair [41].

Dosage of dapsone in chronic inflammatory dermatoses

The dosage of dapsone in nearly all sulfone-sensitive disorders must be individually titrated to determine the minimum daily dose that effectively controls symptoms. Typically, initial dosages in adults range from 50 to $100 \mathrm{mg} /$ day. If the treatment goal is not achieved after 4-6 weeks, a higher dosage may be tried (150-300 mg/day). Administration of higher doses depends on tolerability and the results of laboratory monitoring. When a favourable response is attained, the dosage should then be reduced to the minimum that maintains a satisfactory clinical state.

For administration in children, commercially available tablets of dapsone can be crushed and dissolved, for example, in strawberry syrup. Studies evaluating bioavailability of dapsone after administration of this preparation have not been published. For some indications in childhood, such as infantile acropustulosis or eosinophilic folliculitis, a daily dosage of $2 \mathrm{mg}$ per kilogram of body weight is recommended. Therapy with this dosage, or $4 \mathrm{mg} / \mathrm{kg}$ weekly, results in concentrations equivalent to those reached in adults receiving $100 \mathrm{mg} / \mathrm{day}$. In the treatment of immune thrombocytopenia in children, dapsone was used in a similar dose of about $2 \mathrm{mg} / \mathrm{kg}$ body weight [40].

For topical treatment of acne a twice-daily application is recommended.

\section{Conclusions for treating patients with dapsone}

Contraindications, baseline-monitoring and follow-up controls

Dapsone is contraindicated in patients who are allergic to the drug. It should not be administered to patients with 
severe anaemia. Dapsone must be used with caution in the following conditions:

- Glucose-6-phosphate dehydrogenase deficiency

- Met-Hb-reductase deficiency

- Severe hepatopathy

- Cardiac insufficiency/heart failure

- Pulmonary diseases

- Co-medication with met-Hb-inducing drugs or compounds, respectively

Before initiation of dapsone therapy, patients must undergo a careful clinical evaluation that includes a complete history and physical examination. Routine laboratory checks as listed in Table 7 are recommended. Follow-up visits should include a thorough history to determine adverse effects and incorporate asking for signs of neuropathy. Laboratory tests include a complete blood count with differential and reticulocytes count at least every 2 weeks for the first 3-6 months, and then every 2-4 months. Liver and renal function tests and urinalysis should be performed monthly in the first 3-6 months and then every 2-4 months. Special caution when treating patients with dapsone must be considered in those who are receiving or have been exposed to other drugs or agents that are capable of inducing met-Hb production or haemolysis. In patients with pre-existing anaemia the exact cause of the condition should be clarified by haematologist. For treating patients with dapsone there is no threshold value of haemoglobin. The treatment initiation is based on a range of individual factors (e.g. age, profession, comedication, daily activities, pre-existing pulmonary and/or cardiac diseases). After initiation of dapsone therapy, evaluation of met-Hb levels should be carefully addressed. Different time points are of relevance:

1. Met-Hb generation after a single dapsone dose reaches its maximum after approximately $6 \mathrm{~h}$ and, therefore, undergoes a time-dependent process. In the early

Table 7 Laboratory evaluation before initiation of dapsone therapy

\begin{tabular}{l}
\hline Complete blood count \\
\hline Bilirubin \\
Alanine aminotransferase \\
Aspartate aminotransferase \\
Gamma-glutamyl transferase \\
Creatinine \\
Met-Heamoglobin \\
Glucose-6-phosphate \\
dehydrogenase \\
Serologic test for hepatitis \\
Urinalysis
\end{tabular}

treatment phase met- $\mathrm{Hb}$ should be determined 4-6 h after ingestion of dapsone, because the maximum level of met-Hb in peripheral blood is indicative of real cardiopulmonary risk. For this reason, dapsone intake should be recommended in the evening in patients with activity during the day.

2. Approximately 14 days after initiation of treatment, determination of met-Hb will estimate the level under steady-state conditions and may also allow evaluation of patients adherence to therapy.

3. Other met-Hb determinations must be considered at any time if the patient's condition has changed (e.g., increased dapsone dosage; clinical complaints, comedication with other drugs, starting of smoking, use of pump water in agricultural regions with potential content of nitrites/anilines).

Met-Hb levels do not need to be checked if clinical conditions of the patient remain stable.

Strategies to reduce hematologic adverse effects

$N$-hydroxylation of dapsone via the 3A-family of isoenzymes or CYP 2E1 of the hepatic cytochrome P-450 system leads to the production of DDS-NOH, which has been made responsible for haematologic side effects [35-37, 79, 111, 155]. Against this background, considerable efforts have been made to increase dapsone tolerance. Cytochrome p-450 inhibitors like ketoconazole and cimetidine reduced dapsone-associated formation of met-Hb [32-34, 128]. Coadministration of cimetidine in dosages of $3 \times 400 \mathrm{mg} /$ day reduced met-Hb-levels by $25-30 \%$ in vivo, whereupon this effect surprisingly decreased after 3 months. Coleman recommended to routinely co-administer cimetidine at higher dapsone doses (e.g. $200 \mathrm{mg} /$ day and more) [38]. It has to be borne in mind, however, that DDS-NOH possesses anti-inflammatory effects on its own right. Theoretically, suppressing its production might reduce the therapeutic effects of the parent compound dapsone. This question has not yet been addressed in studies. As another strategy, various antioxidants like ascorbic acid and vitamin $\mathrm{E}$ have been examined. Neither a dose of $1000 \mathrm{mg}$ ascorbic acid/day [89, 127, 146] nor $800 \mathrm{mg}$ vitamin $\mathrm{E}$ had a significant effect on dapsone-induced haemolysis [127]. Only simultaneous application of ascorbic acid and vitamin E exerted an inhibitory effect on met-Hb formation [127]. The reason for these conflicting results might be attributable to the design of the studies which at that time were not GCP-based (no randomization, blinding or placebo controls). For daily practice, in cases of pronounced haematologic adverse effects, co-administration of cimetidine during the first weeks of treatment can be recommended if there are no alternative treatment modalities. 
Potential risk: concomitant use of local anaesthetics

It is well-known that co-medication with other inductors of methaemoglobinaemia as phenacetine and sulphonamides is risky in patients under therapy with dapsone. However, the risk associated with concomitant application of local anaesthetics like benzocaine or lidocaine is often neglected [61]. Cases have been reported where application of local anaesthetics of the amid or ester type as a spray or cream resulted in severe methaemoglobinaemia up to $35 \%$ manifesting right away during surgical procedures. Thus, patients should always carry a dapsone pass and be instructed to present it to their doctors. In elective surgery, dapsone should be stopped a few days earlier. As a precaution, met-Hb levels should be determined before surgery.

\section{Prevention of photosensitivity}

Dapsone is able to suppress UV-induced erythema both when applied orally and topically [166]. However, allergic photosensitivity to dapsone cannot be excluded; but apparently, this is an extremely rare event. So far, less than 20 cases have been reported. As photo-patch tests revealed, the characteristic sulfone group of the parent compound and dapsone metabolites is responsible for the allergic reaction [145]. In view of the suppressive effects of dapsone on UV-induced erythema, it might be wise to advise at least skin type I patients to reckon with increased photosensitivity when dapsone therapy is stopped.

\section{Cross-allergy between dapsone and sulfonamides}

Several lines of evidence suggest that there is no obligatory cross-reactivity between sulfonamides and other sulfonamide-nonantibiotic drugs including dapsone [147]. FDAapproved label for dapsone states that sulfonamide allergy does "not include as a contraindication for dapsone use". Currently, absence of cross-reactivity between dapsone and sulfonamides was confirmed and ascribed to the differential chemical structure of these two drugs [162]. In conclusion, dapsone is not contraindicated in patients with sulfonamide-allergy.

\section{Pregnancy}

Animal reproduction studies with dapsone have not been conducted. Dapsone has been tested in rats and rabbits with concentrations 500- to 800-fold higher than therapeutic levels, when referenced to AUC-value in female patients under therapy with a $5 \%$ dapsone gel. In these studies, dapsone was associated with embryocidal effects [41]. There are, however, no documented noxious effects of dapsone when used in pregnancy [94]. Especially publications about the use of dapsone in the therapy of leprosy suggest that dapsone can be used safely in pregnancy. Multiple case reports about the use of dapsone in a variety of diseases support the assumption of innocuousness. [39, $50,76,97,105,106,109,154,158]$. In any case, the risk of not treating the mother must be weighed up against the risk for the fetus. Dapsone is labelled by US FDA as drug of pregnancy category $\mathrm{C}$. Patients should be informed about the lack of secured data.

In terms of drug interactions and management of acute toxicity of dapsone, the reader is referred to several reviews on this topic $[7,35,41,165]$.

\section{Conclusion}

Dapsone has been studied by far most frequently in vitrounder strictly defined experimental settings. Overall, results of these experiments paint a picture of possible mechanisms of action of dapsone. In addition, many data from human in vivo studies are available including experience in dapsone-sensitive diseases. Nevertheless, we are still far from really understanding dapsone with its differing, in part contradictory facets in most non-infectious diseases. As a result, there are many questions in respect of the mechanisms of action of dapsone that remain to be addressed:

1. In past years much progress in developing molecularbased methods has substantially led to new insights into mechanisms of action of immunosuppressive and/ or immunomodulating remedies including biologics. Therefore, to get more detailed information about the mechanisms of action of dapsone, this panel of investigations should be used with dapsone (e.g., pharmacogenetics) in concentrations comparable with therapeutic conditions.

2. Most of the experimental and clinical studies have been conducted with the parent compound dapsone. Hitherto, the relevance of dapsone metabolites has not been clarified sufficiently. Modern molecular targeted analyses can certainly help to rectify these deficits. This aspect has not yet been addressed at all in the scientific literature.

3. Experimental clues to a preventive effect of dapsone on neurotoxicity require further clarification, as the proposed mechanisms leave room for speculations.

4. Observations of a positive effect of dapsone on lifespan in the Caenorhabditis elegans model raise new questions concerning the inhibition of ageing effects of the sulfone in mammalian cells and organisms. 
5. Finally, dapsone has experienced a renaissance as reference molecule in organic chemistry as efforts are made to synthesize biologically active dapsone analogues like sulfoximine [3, 12, 25, 124]. In this context the definition of the anti-cancer activity of dapsone derivatives currently is of special interest.

Despite that bundle of unanswered questions, dapsone remains an indispensable drug for dermatology and a scientifically fascinating remedy. Discovering dapsone congeners which exhibit the positive therapeutic properties of the original drug but lack unwanted side effects appears desirable.

Open Access This article is distributed under the terms of the Creative Commons Attribution License which permits any use, distribution, and reproduction in any medium, provided the original author(s) and the source are credited.

\section{References}

1. Abe M, Shimizu A, Yokoyama Y, Takeuchi Y, Ishikawa O (2008) A possible inhibitory action of diaminodiphenyl sulfone on tumour necrosis factor-alpha production from activated mononuclear cells on cutaneous lupus erythematosus. Clin Exp Dermatol 33:759-763

2. Ahmad RA, Rogers HJ (1980) Pharmacokinetics and protein binding interactions of dapsone and pyrimethamine. $\mathrm{Br} \mathrm{J}$ Clin Pharmacol 10:519-524

3. Al-Said MS, Ghorab MM, Nissan YM (2012) Dapson heterocytic chemistry, part VIII: synthesis, molecular docking and anticancer activity of some novel sulfonylbiscompounds carrying biologically active 1,3-dihydropyridine, chromene and chromenopyridine moieties. Chem Cent J 6:64

4. Altagracia M, Monroy-Noyola A, Osorio-Rico L, Kravzov J, Varado-Calvillo R, Manjarrez-Marmolejo J, Rios C (1994) Dapsone attenuates kainic acid-induced seizures in rats. Neurosci Lett 176:52-54

5. Anderson R, Gatner EM, van Rensburg CE, Grabow G, Imkamp FM, Kok SK, van Rensburg AJ (1981) In vitro and in vivo effects of dapsone on neutrophil and lymphocyte functions in normal individuals and patients with lepromatous leprosy. Anitmicrob Agents Chemother 19:495-503

6. Anderson R (1985) Enhancement by clofazimine and inhibition by dapsone of production of prostaglandin E2 by human polymorphonuclear leukocytes in vitro. Antimicrob Agents Chemother 27:257-362

7. Ashurst JV, Wasson MN, Hauger W, Fritz WT (2010) Pathophysiologic mechanisms, diagnosis, and management of dapsone-induced methemoglobinemia. J Am Osteopath Assoc 110:16-20

8. Barranco VP (1974) Inhibition of lysosomal enzymes by dapsone. Arch Dermatol 110:563-566

9. Beiguelman B, Pisam RC (1974) Effect of DDS on phytohemagglutinin-induced lymphocyte transformation. Int J Lepr Other Mycobact Dis 42:412-415

10. Berlow BA, Liebhaber MI, Dyer Z, Spiegel TM (1991) The effect of dapsone in steroid-dependent asthma. J Allergy Clin Immunol 87:710-715

11. Bernstein JE, Lorincz AL (1981) Sulfonamides and sulfones in dermatologic therapy. Int J Dermatol 20:81-88
12. Bissinger EM, Heinke R, Spannhoff A, Eberlin A, Metzger E, Cura V, Hassenboehler P, Cavarelli J, Schüle R, Bedford MT, Sippl W, Jung M (2011) Acyl derivatives of p-aminosulfonamides and dapsone as new inhibitors of the arginine methyltransferase hPRMT1. Bioorg Med Chem 29:3717-3731

13. Blasum C (1998) Untersuchung zur Beinflussung der Interleukin-8-Spiegel in Lipopolysaccharid-stimulierten Vollblut gesunder Probanden durch in der Dermatologie angewandte antiinflammatorische Pharmaka mit antioxidativer Potenz. (Thesis). Technical University, University Hospital, Department of Dermatology, Dresden

14. Boehm I, Bauer R, Bieber T (1999) Urticaria treated with dapsone. Allergy 54:765-766

15. Bonney RJ, Wightman PD, Dahlgren ME, Sadowski SJ, Davies P, Jensen N, Lanza T, Humes JL (1983) Inhibition of the release of prostaglandins, leukotrienes and lysosomal acid hydrolases from macrophages by selective inhibitors of lecithin biosynthesis. Biochem Pharmacol 32:361-366

16. Booth SA, Moody CE, Dahl MV, Herron MJ, Nelson RD (1992) Dapsone suppresses integrin-mediated neutrophil adherence function. J Invest Dermatol 98:135-140

17. Bordin L, Fiore C, Zen F, Coleman MD, Ragazzi E, Clari G (2010) Dapsone hydroxylamine induces premature removal of human erythrocytes by membrane reorganization and antibody binding. Br J Pharmacol 161:1186-1199

18. Boyer H, Nitti F, Tréfouel J (1937) Note preliminaire sur l'action de la paradiacetyl-aminodiphenyl sulfone (1399F) dans la blennorrhagic. Bul Soc Fr Dermatol Syphiligr 44:1889

19. Bozeman PM, Learn DB, Thomas EL (1992) Inhibition of the human leukocyte enzymes myeloperoxidase and eosinophil peroxidase by dapsone. Biochem Pharmacol 44:553-563

20. Branski D, Kerem E, Gross-Kieselstein E, Hurvitz H, Litt R, Abrahamov A (1986) Bloody diarrhea-a possible complication of sulfasalazine transferred through human breast milk. J Pediatr Gastroenterol Nutr 5:316-317

21. Bundino S, Zina AM, Ubertalli S (1982) Infantile acropustulosis. Dermatologica 165:615-619

22. Buttle GAH, Stephenson D, Smith T, Dewing T, Foster GE (1937) The treatment of streptococcal infections in mice with 4:2'diaminodiphenylsulfone. Lancet 229:1331-1334

23. Capstick RB, Lewis DA (1977) Aspects of the biochemistry and toxicology of dapsone and azapropazone. Drugs Exp Clin Res 2:79-87

24. Cassano N, D'Argento V, Filotico R, Vena GA (2005) Lowdose dapsone in chronic idiopathic urticaria: preliminary results of an open study. Acta Derm Venereol 85:254-255

25. Chen XY, Buschmann H, Bolm C (2012) Sulfoximine- and sulfilimine-based DAPSON analogs: syntheses and bioactivities. Synlett 23:2808-2810

26. Cho SC, Park MC, Keam B, Choi JM, Cho Y, Hyun S, Park SC, Lee J (2010) DDS,4,4'-diaminodiphenylsulfone, extends organismic lifespan. Proc Natl Acad Sci USA 107:19326-19331

27. Cho SC, Rhim JH, Son YH, Lee SJ, Park SC (2010) Suppression of ROS generation by 4,4-diaminodiphenylsulfone in nonphagocytic human diploid fibroblasts. Exp Mol Med 42:223-232

28. Cho SC, Rhim JH, Choi HR, Son YH, Lee SJ, Song KY, Park SC (2011) Protective effect of 4,4'-diaminodiphenylsulfone against paraquat-induced mouse lung injury. Exp Mol Med 43:525-537

29. Christoph H (1991) Experimentelle In-vivo-Untersuchungen von potentiellen topischen Antipsoriatika bzw. Antiphlogistika im Arachidonsäure-induzierten Mäuseohrschwellungstest (AAMest) (Thesis). Technical University, University Hospital, Department of Dermatology, Dresden

30. Cohen PR (2009) Neutrophilic dermatoses: a review of current treatment options. Am J Clin Dermatol 10:301-312 
31. Cohen DM, Ben-Amitai D, Feinmesser M, Zvulunov A (2009) Childhood lichen planus pemphigoides: a case report and review of the literature. Pediatr Dermatol 26:569-574

32. Coleman MD, Scott AK, Breckenridge AM, Park BK (1990) The use of cimetidine as a selective inhibitor of dapsone $\mathrm{N}$ hydroxylation in man. Br J Clin Pharmacol 30:761-767

33. Coleman MD, Rhodes LE, Scott AK, Verbov JL, Friedmann PS, Breckenridge AM, Park BK (1992) The use of cimetidine to reduce dapsone-dependent methaemoglobinaemia in dermatitis herpetiformis patients. Br J Clin Pharmacol 34:244-249

34. Coleman MD, Russell RM, Tingle MD, Park BK (1992) Inhibition of dapsone-induced methaemoglobinaemia by cimitidine in the presence of trimethoprim in the rat. J Pharm Pharmacol 44:114-118

35. Coleman MD (1993) Dapsone: modes of action, toxicity and possible strategies for increasing patient tolerance. Br J Dermatol 129:507-513

36. Coleman MD, Jacobus DP (1993) Reduction of dapsone hydroxylamine to dapsone during methaemoglobin formation in human erythrocytes in vitro-II. Movement of dapsone across a semipermeable membrane into erythrocytes and plasma. Biochem Pharmacol 46:1363-1368

37. Coleman MD, Jacobus DP (1993) Reduction of dapsone hydroxylamine to dapsone during methaemoglobin formation in human erythrocythes in vitro. Biochem Pharmacol 45:1027-1033

38. Coleman MD (1995) Dapsone toxicity: some current perspectives. Gen Pharmacol 26:1461-1467

39. Collier PM, Kelly SE, Wojnarowska F (1994) Linear IgA disease and pregnancy. J Am Acad Dermatol 30:407-411

40. Damodar S, Viswabandya A, George B, Mathews V, Chandy M, Srivastava A (2005) Dapsone for chronic idiopathic thrombocytopenic purpura in children and adults-a report on 90 patients. Eur J Haematol 75:328-331

41. Dapsone (2011) In: McEvoy GK (ed) AHFS drug information. American Society of Health-System Pharmacists, Bethesda (MD), pp 622-626

42. Dayani A, Gould DJ, Cambell S (1992) Delayed pressure urticaria: treatment with dapsone. J Dermatolog Treat 3:61-62

43. Debol SM, Herron MJ, Nelson RD (1997) Anti-inflammatory action of dapsone: inhibition of neutrophil adherence is associated with inhibition of chemoatractant-induced signal transduction. J Leukoc Biol 62:827-836

44. DeForge LE, Fantone JC, Kenney JS, Remick DG (1992) Oxygen radical scavengers selectively inhibits interleukin 8 production in human whole blood. J Clin Invest 90:21232129

45. DeLeo VA, Scheide S, Horlich H, Southern W, Harber LC, Weinstein IB (1986) The effect of 12-O-tetradecanoylphorbol13-acetate (TPA) on phospholipid metabolism of human epidermal keratinocytes in culture. Carcinogenesis 7:937-942

46. Diaz-Ruiz A, Zavala C, Montes S, Ortiz-Plata A, Salgado-Ceballos H, Orozco-Suarez S, Nava-Ruiz C, Pérez-Neri I, PérezSeveriano F, Rios C (2008) Antioxidant, anti-inflammatory and antiapoptotic effects of dapsone in a model of brain ischemia/ reperfusion in rats. J Neurosci Res 86:3410-3419

47. Doull JA (1963) Sulfone therapy of leprosy. Background, early history and present status. Int J Lepr 31:143-160

48. Draelos ZD, Carter E, Maloney JM, Elewski B, Poulin Y, Lynde C, Garrett S (2007) Two randomized studies demonstrate the efficacy and safety of dapsone gel, $5 \%$ for the treatment of acne vulgaris. J Am Acad Dermatol 56:439e1-439e10

49. Drayer DE, Strong JM, Jones B, Sandler A, Reidenbeg MM (1974) In vitro acetylation of drugs by human blood cells. Drug Metab Dispos 2:499-505

50. Duncan ME, Pearson JM, Rees RJ (1981) The association of pregnancy and leprosy. II. Pregnancy in dapsone-resistant leprosy. Lepr Rev 52:263-270
51. Durand JM, Lefevre P, Hovette P, Issifi S, Mongin M (1991) Dapsone for thrombocytopenic purpura related to human immunodeficiency virus infection. Am J Med 90:675-677

52. Durand JM, Lefèvre P, Hovette P, Mongin M, Soubeyrand J (1991) Dapsone for idiopathic autoimmune thrombocytopenic purpura in elderly patients. Br J Haematol 78:459-460

53. Engin B, Ozdemir M (2008) Prospective randomized non-blinded clinical trial on the use of dapsone plus antihistamine vs. antihistamine in patients with chronic idiopathic urticaria. J Eur Acad Dermatol Venereol 22:481-486

54. Esca SA, Pehamberger H, Silny W, Holubar K (1981) Polymorphonuclear leukocyte chemotaxis in dermatitis herpetiformis. Acta Derm Venereol 61:61-63

55. Esterly NB, Furey NL, Flanagan LE (1978) The effect of antimicrobial agents on leukocyte chemotaxis. J Invest Dermatol 70:51-55

56. Esteves J, Brãndao F (1950) Acerca da açcão das sulfamidas e das sulfonas na doença de Duhring. Trab Soc Port Dermatol Venereol 8:209-217

57. Faget GH, Pogge RC, Johansen FA, Dinan JF, Prejean BM, Eccles CG (1943) The promin treatment of leprosy. Public Health Rep 58:1729-1741

58. Fonacier L, Aquino M, Kim B (2010) Clinical evaluation and treatment of chronic urticaria. Postgrad Med 122:148-156

59. Fourneau E, Trèfouel J, Nitti F, Bovet D, Tréfouel J (1937) Action anti-streptococcique des dérivés sulfurés organiques. C R Acad Sci 204:1763-1766

60. Fräki JE, Hopsu-Havu VK (1977) Inhibition of human skin proteinases by chloroquine, dapsone and sulfapyridine. Arch Dermatol Res 259:113-115

61. Frayling IM, Addison GM, Chattergee K, Meakin G (1990) Methaemoglobinaemia in children treated with prilocainelignocaine cream. BMJ 301:153-154

62. Fredenberg MF, Malkinson FD (1987) Sulfone therapy in the treatment of leukocytoclastic vasculitis. Report of three cases. J Am Acad Dermatol 16:772-778

63. Fromm E, Wittmann J (1908) Derivate des p-nitrothiophenols. Ber Dtsch Chem Ges 41:2264-2273

64. Gemmell DK, Cottney J, Lewis AJ (1979) Comparative effects of drugs on four paw oedema models in the rat. Agents Actions 9:107-116

65. Grabbe J, Haas N, Möller A, Henz BM (2000) Erythema elevatum diutinum-evidence for disease-dependent leucocyte alterations and response to dapsone. Br J Dermatol 143:415-420

66. Grundmann SA, Kiefer S, Luger TA, Brehler R (2011) Delayed pressure urticaria-dapsone heading for first-line therapy? J Dtsch Dermatol Ges 9:908-912

67. Grunwald MH, Amichai B (1996) Dapsone-the treatment of infectious and inflammatory diseases in dermatology. Int J Antimicrob Agents 7:187-192

68. Gürcan HM, Ahmed AR (2009) Efficacy of dapsone in the treatment of pemphigus and pemphigoid: analysis of current data. Am J Clin Dermatol 10:383-396

69. Haar D, Sølvkjaer M, Unger B, Rasmussen KJ, Christensen L, Hansen TM (1993) A double-blind comparative study of hydroxychloroquine and dapsone, alone and in combination, in rheumatoid arthritis. Scand J Rheumatol 22:113-118

70. Hamada K, Hiyoshi T, Kobayashi S, Ishida S, Yagi K, Seino M (1991) Anticonvulsive effect of dapsone (4,4'-diaminodiphenyl sulfone) on amygdala-kindled seizures in rats and cats. Epilepsy Res 10:93-102

71. Hargrave D (2009) Paediatric high and low grade glioma: the impact of tumour biology on current and future therapy. Br J Neurosurg 23:351-363

72. Harvath L, Yancey K, Katz S (1986) I. Selective inhibition of human neutrophil chemotaxis to $N$-formyl-methionyl-leucylphenylalanine by sulfones. J Immunol 137:1305-1311 
73. Hashimoto K, Singer K, Lazarus GS (1984) The effect of corticosteroids, dapsone and gold upon plasminogen activator synthesis and secretion by human epidermal cells cultured with pemphigus antibody. Br J Dermatol 110:293-297

74. Hegarty AM, Ormond M, Sweeney M, Hodgson T (2010) Dapsone efficacy and adverse events in the management of mucous membrane pemphigoid. Eur J Dermatol 20:223-224

75. Henz BM, Zuberbier T, Grabbe J, Monroe E (eds) (1998) Urticarias. Clinical, diagnostic and therapeutic aspects. Springer, Berlin

76. Hocking DR (1968) Neonatal haemolytic disease due to dapsone. Med J Aust 1:1130-1131

77. Homeida M, Babikr A, Daneshmend TK (1980) Dapsoneinduced optic atrophy and motor neuropathy. $\mathrm{Br}$ Med $\mathrm{J}$ 281:1180

78. Ishida S, Hamada K, Yagi K, Seino M (1992) Comparing the anticonvulsive effects of dapsone on amygdala-kindled seizures and hippocampal-kindled seizures in rats. Acta Neurol Scand 85:132-135

79. Israili ZH, Cucinell SA, Vaught J, Davis E, Lesser JM, Dayton PG (1973) Studies of the metabolism of dapsone in man and experimental animals: formation of $N$-hydroxy metabolites. J Pharmacol Exp Ther 187:138-151

80. Kanoh S, Tanabe T, Rubin BK (2011) Dapsone inhibits IL-8 secretion from human bronchial epithelial cells stimulated with lipopolysaccharide and resolves airway inflammation in the ferret. Chest 140:980-990

81. Kar BR (2008) Dapsone-induced photosensitivity: a rare clinical presentation. Photodermatol Photoimmunol Photomed 24:270-271

82. Kardos M, Levine D, Gurcan HM, Ahmed RA (2009) Pemphigus vulgaris in pregnancy: analysis of current data on the management and outcomes. Obstet Gynecol Surv 64:739-749

83. Kasperkiewicz M, Zillikens D (2007) The pathophysiology of bullous pemphigoid. Clin Rev Allergy Immunol 33:67-77

84. Kasperkiewicz M, Schmidt E (2009) Current treatment of autoimmune blistering diseases. Curr Drug Discov Technol $6: 270-280$

85. Kast RE, Scheuerle A, Wirtz CR, Karpel-Massler G, Halatsch ME (2011) The rationale of targeting neutrophils with dapsone during glioblastoma treatment. Anticancer Agents Med Chem 11:756-761

86. Kast RE, Lefrance F, Karpel-Massler G, Halatsch ME (2012) Why dapsone stops seizures and may stop neutrophils' delivery of VEGF to glioblastoma. Br J Neurosurg 26:813-817

87. Katz SI, Hertz KC, Crawford PS, Gazze LA, Frank MM, Lawley TJ (1976) Effect of sulfones on complement deposition in dermatitis herpetiformis and on complement-mediated guinea-pig reactions. J Invest Dermatol 67:688-690

88. Kazmierowski JA, Ross JE, Peizner DS, Wuepper KD (1984) Dermatitis herpetiformis: effects of sulfones and sulfonamides on neutrophil myeloperoxidase-mediated iodination and cytotoxicity. J Clin Immunol 4:55-64

89. Kelly JW, Scott J, Sandland M, Van der Weyden MB, Marks R (1984) Vitamin E and dapsone-induced hemolysis. Arch Dermatol 120:1582-1584

90. Kelso JM, Bai CL, Ahokas JT, Wright PF (1997) In vitro effects of MOCA and dapsone on rat hepatic and splenic immune cells. Immunopharmacology 35:183-193

91. Kenner DJ, Holt K, Agnello R, Chester GH (1980) Permanent retinal damage following massive dapsone overdose. $\mathrm{Br} \mathrm{J}$ Ophthalmol 64:741-744

92. Kettle AJ, Winterbourn CC (1991) Mechanism of inhibition of myeloperoxidase by anti-inflammatory drugs. Biochem Pharmacol 41:1485-1492
93. Kettle AJ, Gedye CA, Winterbourn CC (1993) Superoxide is an antagonist of anitinflammatory drugs that inhibit hypochlorous acid production by myeloperoxidase. Biochem Pharmacol 45:2003-2010

94. Khan G (1985) Dapsone is safe during pregnancy. J Am Acad Dermatol 13:838-839

95. Khan FD, Roychowdhury S, Nemes R, Vyas PM, Woster PM, Svensson CK (2006) Effect of pro-inflammatory cytokines on the toxicity of the arylhydroxylamine metabolites of sulphamethoxazole and dapsone in normal human keratinocytes. Toxicology 218:90-99

96. Kim SM, Kim DS, Jeong CH, Kim DH, Kim JH, Jeon HB, Kwon SJ, Jeun SS, Yang YS, Oh W, Chang JW (2011) CXC chemokine receptor 1 enhances the ability of human umbilical cord blood-derived mesenchymal stem cells to migrate toward gliomas. Biochem Biophys Res Commun 407:741-746

97. King JA, Marks RA (1958) Pregnancy and leprosy; a review of 52 pregnancies in 26 patients with leprosy. Am J Obstet Gynecol 76:438-442

98. Knudson RM, Kalaaji AN, Bruce AJ (2010) The management of mucous membrane pemphigoid and pemphigus. Dermatol Ther 23:268-280

99. Kumar B, Ganguly NK, Kaur S, Vaishnavi C, Chakravarti RN (1983) Effect of dapsone (DDS) on T-cells and their response to PHA and lepromin in tuberculoid leprosy patients. Lepr India 55:465-471

100. Lammers AM, van de Kerkhof PC, Schalwijk J, Mier PD (1986) Elastase, a marker for neutrophils in skin infiltrates. Br J Dermatol 115:181-186

101. Lang PG Jr (1979) Sulfones and sulfonamides in dermatology today. J Am Acad Dermatol 1:479-492

102. Lewis AJ, Gemmell DK, Stimson WH (1978) The anti-inflammatory profile of dapsone in animal models of inflammation. Agents Actions 8:578-586

103. Lopez-Gomez M, Corona T, Diaz-Ruiz A, Rios C (2011) Safety and tolerability of dapsone for the treatment of patients with drug-resistant, partial-onset seizures: an open-label trial. Neurol Sci 32:1063-1067

104. Lorenz M, Wozel G, Schmitt J (2012) Hypersensitivity reactions to dapsone: a systematic review. Acta Derm Venereol 92:194-199

105. Lowe J (1952) Studies in sulphone therapy. Lepr Rev 23:4-29

106. Lush R, Iland H, Peat B, Young G (2000) Successful use of dapsone in refractory pregnancy-associated idiopathic thrombocytopenic purpura. Aust N Z J Med 30:105-107

107. Maloff BL, Fox D, Bruin E, Di Meo TM (1988) Dapsone inhibits LTB4 binding and bioresponse at the cellular and physiologic levels. Eur J Pharmacol 158:85-89

108. Maurer M, Altrichter S, Ardelean E, Krause K, Magerl M, Metz M, Siebenhaar F, Weller K, Zuberbier T (2010) Therapeutic alternatives for antihistamine-refractory urticaria. Hautarzt 61:765-769

109. Maurus JN (1978) Hansen's disease in pregnancy. Obstet Gynecol 52:22-25

110. Millar BW, Macdonald KJ, Macleod TM, Raffle EJ (1984) Dapsone and human polymorphonuclear leucocyte chemotaxis in dermatitis herpetiformis. Acta Derm Venereol 64:433-436

111. Mitra AK, Thummel KE, Kalhorn TF, Kharasch ED, Unadkat JD, Slattery JT (1995) Metabolism of dapsone to its hydroxylamine by CYP2E1 in vitro and in vivo. Clin Pharmacol Ther 58:556-566

112. Miyachi Y, Niwa Y (1982) Effects of potassium iodide, colchicine and dapsone on the generation by normal polymorphonuclear leukocyte-derived oxygen intermediates. Br J Dermatol 107:209-214 
113. Miyachi Y, Yanase K, Imamura S, Niwa Y (1982) Increased hydroxyl radical generation by normal polymorphonuclear leukocytes incubated in sera from patients with leukocytoclastic vasculitis. Arch Dermatol Res 274:65-71

114. Miyachi Y, Niwa Y (1983) Effects of psoriatic sera on the generation of oxygen intermediates by normal polymorphonuclear leucocytes. Arch Dermatol Res 275:23-26

115. Miyachi Y, Yoshioka A, Horio T, Imamura S, Niwa Y (1986) Prurigo pigmentosa: a possible mechanism of action of sulfonamides. Dermatologica 172:82-88

116. Modschiedler K, Weller M, Wörl P, von den Driesch P (2000) Dapsone and colchicine inhibit adhesion of neutrophilic granulocytes to epidermal sections. Arch Dermatol Res 292:32-36

117. Mukaida N (2000) Interleukin-8: an expanding universe beyond neutrophil chemotaxis and activation. Int J Hematol 72:391-398

118. Nader-Kawachi J, Gongora-Rivera F, Santos-Zambrano J, Calzada P, Rios C (2007) Neuroprotective effect of dapsone in patients with acute ischemic stroke: a pilot study. Neurol Res 29:331-334

119. Nagata Y, Koshaka K, Ito T (1985) Negative observations on immunological side effects of rifampin and dapsone in mice. Int J Lepr Other Mycobact Dis 53:421-427

120. Nicholas MK, Lukas RV, Chmura S, Yamini B, Lesniak M, Pytel P (2011) Molecular heterogeneity in glioblastoma: therapeutic opportunities and challenges. Semin Oncol 38:243-253

121. Niwa Y, Sakane T, Miyachi Y (1984) Dissociation of the inhibitory effect of dapsone on the generation of oxygen intermediates-in comparison with that of colchicine and various scavengers. Biochem Pharmacol 33:2355-2360

122. Niwa Y, Miyachi Y (1985) Inhibitor effects of dapsone on enzymatic acitivities of membrane phospholipids in human blood cells. Arch Dermatol Res 277:473-477

123. Palazzoli M, Bovet D (1937) Action de la di(paracetylaminophenyl)sulfone (1399F) dans les urétrites gonococciques aiguës et chroniques. Bull Soc Fr Dermatol Syphiligr 44:1900

124. Park BK, Boobis A, Clarke S, Goldring CE, Jones D, Kenna JG, Lambert C, Laverty HG, Naisbitt DJ, Nelson S, Nicoll-Griffith DA, Obach RS, Routledge P, Smith DA, Tweedie DJ, Vermeulen N, Williams DP, Wilson ID, Baillie TA (2011) Managing the challenge of chemically reactive metabolites in drug development. Nat Rev Drug Discov 10:292-306

125. Pfeiffer G, Wozel G (2003) Dapsone and sulfones in dermatology: overview and update. J Am Acad Dermatol 48:308-309

126. Piette EW, Werth VP (2011) Dapsone in the management of autoimmune bullous diseases. Dermatol Clin 29:561-564

127. Prussick R, Ali MA, Rosenthal D, Guyatt G (1992) The protective effect of vitamin $\mathrm{E}$ on the hemolysis associated with dapsone treatment in patients with dermatitis herpetiformis. Arch Dermatol 128:210-213

128. Rhodes LE, Tingle MD, Park BK, Chu P, Verbov JL, Friedmann PS (1995) Cimetidine improves the therapeutic/toxic ratio of dapsone patients on chronic dapsone therapy. Br J Dermatol 132:257-262

129. Rios C, Nader-Kawachi J, Rodriguez-Payán AJ, Nava-Ruiz C (2004) Neuroprotective effect of dapsone in an occlusive model of focal ischemia in rats. Brain Res 999:212-215

130. Rodríguez E, Méndez-Armenta M, Villeda-Hernández J, Galván-Arzate $\mathrm{S}$, Barroso-Moguel $\mathrm{R}$, Rodríguez $\mathrm{F}$, Rios $\mathrm{C}$, Santamaria A (1999) Dapsone prevents morphological lesions and lipid peroxidation induced by quinolinic acid in rat corpus striatum. Toxicology 139:111-118

131. Ruzicka T, Bauer A, Glück S, Born M (1981) Effects of dapsone on passive Arthus reaction and chemotaxis and phagocytosis of polymorphonuclear leukocytes. Arch Dermatol Res 270:347-351
132. Ruzicka T, Goerz G (1981) Systemic lupus erythematosus and vasculitic urticaria. Effect of dapsone and complement levels. Dermatologica 162:203-205

133. Ruzicka T, Goerz G (1981) Dapsone in the treatment of lupus erythematosus. Br J Dermatol 104:53-56

134. Ruzicka T, Wasserman SI, Soter NA, Printz MP (1983) Inhibition of rat mast cell arachidonic acid cyclooxygenase by dapsone. J Allergy Clin Immunol 72:365-370

135. Salomon K (2000) Humane In-vivo-Untersuchungen zur antientzündlichen Wirksamkeit von Diaminodiphenylsulfon (Dapson). (Thesis). Technical University, University Hospital, Department of Dermatology, Dresden

136. Samsoen M, Bousquet F, Basset A (1981) Sulfones. Indications excluding infectious diseases. Ann Dermatol Venereol 108:911-920

137. Sanders SW, Zone JJ, Foltz RL, Tolman KG, Rollins DE (1982) Hemolytic anemia induced by dapsone transmitted through breast milk. Ann Intern Med 96:465-466

138. Santamaria A, Ordaz-Moreno J, Rubio-Osornio M, Solís-Hernández F, Rios C (1997) Neuroprotective effect of dapsone against quinolinate- and kainate-induced striatal neurotoxicities in rats. Pharmacol Toxicol 81:271-275

139. Schmidt E, Reimer S, Kruse N, Brocker EB, Zillikens D (2001) The IL-8 release from cultured human keratinocytes, mediated by antibodies to bullous pemphigoid autoantigen 180, is inhibited by dapsone. Clin Exp Immunol 124:157-162

140. Sengupta U, Ghei SK, Venkatesan K, Bharadwaj VP (1979) In vivo effect of DDS on phytohemagglutinin (PHA)-induced lymphocyte transformation cultures in normal healthy volunteers. Int J Lepr Other Mycobact Dis 47:167-170

141. Shibata K, Tateishi T, Yamasaki R, Ohyagi Y, Kira J (2010) Successful treatment of a case of steroid-dependent neuro-Sweet disease with dapsone. Rinsho Shinkeigaku 50:257-261

142. Smith LC, Cox NH (2008) Dapsone treatment for eosinophilic fasciitis. Arch Dermatol 144:845-847

143. Sneddon IB, Wilkinson DS (1956) Subcorneal pustular dermatosis. Br J Dermatol 68:385-394

144. Stendahl O, Molin L, Dahlgren C (1978) The inhibition of polymorphonuclear leukocyte by dapsone. A possible mechanism in the treatment of dermatitis herpetiformis. J Clin Invest 62:214-220

145. Stöckel S, Meurer M, Wozel G (2001) Dapsone-induced photodermatitis in a patient with linear $\operatorname{IgA}$ dermatosis. Eur $\mathrm{J}$ Dermatol 11:50-53

146. Stratton LP, Rudolph AS, Knoll WK Jr, Bayne S, Farmer MC (1988) The reduction of methemoglobin levels by antioxidants. Hemoglobin 12:353-368

147. Strom BL, Schinnar R, Apter AJ, Margolis DJ, Lautenbach E, Hennessy S, Bilker WB, Pettitt D (2003) Absence of crossreactivity between sulfonamide antibiotics and sulfonamide nonantibiotics. N Engl J Med 349:1628-1635

148. Suda T, Suzuki Y, Matsui T, Inoue T, Niide O, Yoshimaru T, Suzuki H, Ra C, Ochiai T (2005) Dapsone suppresses human neutrophil superoxide production and elastase release in a calcium-dependent manner. Br J Dermatol 152:887-895

149. Theron A, Anderson R (1985) Investigation of the protective effects of the antioxidants ascorbate, cysteine, and dapsone on the phagocyte-mediated oxidative inactivation of human alpha1-protease inhibitor in vitro. Am Rev Respir Dis 132:1049-1054

150. Thompson DM, Souhami R (1975) Suppression of the arthus reaction in the guinea-pig by dapsone. Proc R Soc Med 68:273

151. Thuong-Nguyen V, Kadunce DP, Hendrix JD, Gammon WR, Zone JJ (1993) Inhibition of neutrophil adherence to antibody by dapsone: a possible therapeutic mechanism of dapsone in the treatment of IgA dermatoses. J Invest Dermatol 100:349-355 
152. Tingle MD, Mahmud R, Maggs JL, Pirmohamed M, Park BK (1997) Comparison of the metabolism and toxicity of dapsone in rat, mouse and man. J Pharmacol Exp Ther 283:817-823

153. Tirado-Sanchez A, Diaz-Molina V, Ponce-Olivera RM (2012) Efficacy and safety of azathioprine and dapsone as an adjuvant in the treatment of bullous pemphigoid. Allergol Immunopathol (Madr) 40:152-155

154. Tuffanelli DL (1982) Successful pregnancy in a patient with dermatitis herpetiformis treated with low-dose dapsone. Arch Dermatol 118:876

155. Uehleke H, Taberelli S (1973) $N$-hydroxylation of $4,4^{\prime}$-diaminodiphenylsulphone (Dapsone) by liver microsomes, and in dogs and humans. Naunyn Schmiedebergs Arch Pharmacol 278:55-68

156. Uetrecht J, Zahid N, Shear NH, Biggar WD (1988) Metabolism of dapsone to a hydroxylamine by human neutrophils and mononuclear cells. J Pharmacol Exp Ther 245:274-279

157. van Zyl JM, Basson K, Kriegler A, van der Walt BJ (1991) Mechanisms by which clofazimine and dapsone inhibit the myeloperoxidase system. A possible correlation with their antiinflammatory properties. Biochem Pharmacol 42:599-608

158. Varghese L, Viswabandya A, Mathew AJ (2008) Dapsone, danazol, and intrapartum splenectomy in refractory ITP complicating pregnancy. Indian J Med Sci 62:452-455

159. Veggi LM, Pretto L, Ochoa EJ, Catania VA, Luquita MG, Taborda DR, Sánchez Pozzi EJ, Ikushiro S, Coleman MD, Roma MG, Mottino AD (2008) Dapsone induces oxidative stress and impairs antioxidant defenses in rat liver. Life Sci 83:155-163

160. Walker JG, Kadia T, Brown L, Juneja HD, de Groot JF (2009) Dapsone induced methemoglobinemia in a patient with glioblastoma. J Neurooncol 94:149-152

161. Webster GF, Alexander JC, McArthur WP, Leyden JJ (1984) Inhibition of chemiluminescence in human neutrophils by dapsone. Br J Dermatol 110:657-663

162. Webster GF (2010) Is topical dapsone safe in glucose-6-phosphate dehydrogenase-deficient and sulfonamide-allergic patients? J Drugs Dermatol 9:532-536

163. Weiss SJ (1989) Tissue destruction by neutrophils. N Engl J Med 320:365-376

164. Wolf R, Tüzün B, Tüzün Y (2000) Dapsone: unapproved uses or indications. Clin Dermatol 18:37-53

165. Wozel G (1996) Dapson-Pharmakologie. Wirkmechanismus und klinischer Einsatz, Thieme, Stuttgart

166. Wozel G, Blümlein K, Blasum C, Lehmann B, Winter C (1999) Comments on:"Preventive effect of dapsone on renal scarring following mannose-sensitive piliated bacterial infection" by
Mochida et al. (Chemotherapy 1998; 44:36-41). Chemotherapy 45:233-235

167. Wozel G, Thiele B (1987) Urticaria vasculitis and sulfone, a case report. Z Hautkr 62:407-409

168. Wozel G, Köstler E, Barth J (1988) Results of therapy studies with anti-inflammatory substances in occlusive conditions in psoriasis. Dermatol Monatsschr 174:421-423

169. Wozel G, Barth J (1988) Current aspects of modes of action of dapsone. Int J Dermatol 27:547-552

170. Wozel G (1989) The story of sulfones in tropical medicine and dermatology. Int J Dermatol 28:17-21

171. Wozel G, Lehmann B (1995) Dapsone inhibits the generation of 5-lipoxygenase products in human polymorphonuclear leukocytes. Skin Pharmacol 8:196-202

172. Wozel G, Blasum C, Winter C, Gerlach B (1997) Dapsone hydroxylamine inhibits the LTB4-induced chemotaxis of polymorphonuclear leukocytes into human skin: results of a pilot study. Inflamm Res 46:420-422

173. Wozel G (2010) Innovative use of dapsone. Dermatol Clin 28:599-610

174. Xia M, Qin S, McNamara M, Mackay C, Hyman BT (1997) Interleukin-8 receptor B immunoreactivity in brain and neuritic plaques of Alzheimer's disease. Am J Pathol 150:1267-1274

175. Yazdanyar S, Boer J, Ingvarsson G, Szepietowski JC, Jemec GB (2011) Dapsone therapy for hidradenitis suppurativa: a series of 24 patients. Dermatology 222:342-346

176. Zaja F, Marin L, Chiozzotto M, Puglisi S, Volpetti S, Fanin R (2012) Dapsone salvage therapy for adult patients with immune thrombocytopenia relapsed or refractory to steroid and rituximab. Am J Hematol 87:321-323

177. Zhu KJ, He FT, Jin N, Lou JX, Cheng H (2009) Complete atrioventricular block associated with dapsone therapy: a rare complication of dapsone-induced hypersensitivity syndrome. J Clin Pharm Ther 34:489-492

178. Zhu YI, Stiller MJ (2001) Dapsone and sulfones in dermatology: overview and update. J Am Acad Dermatol 45:420-434

179. Zone JJ, Meyer LJ (1989) Dermatitis herpetiformis. Immunol Ser 46:565-582

180. Zubebier T, Aberer W, Brockow K, Grabbe J, Hamelmann E, Hartmann K, Jakob T, Maurer M, Merk HF, Ollert M, Ruëff F, Schmid-Grendelmeier P, Staubach P, Voigtmann I, Wedi B (2011) Teil 2: therapie der Urtikaria—deutschsprachige Version der internationalen S3-Leitlinie. Allergo J 20:259-276

181. Zuidema J, Hilbers-Modderman ES, Merkus FW (1986) Clinical pharmacokinetics of dapsone. Clin Pharmacokinet 11:299-315 